\title{
Integrated analysis of expression, prognostic value and immune infiltration of GSDMs in hepatocellular carcinoma
}

\author{
Kuan $\mathrm{Hu}^{1}$, Zhijie $\mathrm{Xu}^{2}$, Lei Yao ${ }^{1}$, Yuanliang Yan ${ }^{3,4}$, Lei Zhou ${ }^{5}$, Juanni $\mathrm{Li}^{2}$ \\ ${ }^{1}$ Department of Hepatobiliary Surgery, Xiangya Hospital, Central South University, Changsha 410008, Hunan, \\ China \\ ${ }^{2}$ Department of Pathology, Xiangya Hospital, Central South University, Changsha 410008, Hunan, China \\ ${ }^{3}$ Department of Pharmacy, Xiangya Hospital, Central South University, Changsha 410008, Hunan, China \\ ${ }^{4}$ National Clinical Research Center for Geriatric Disorders, Xiangya Hospital, Central South University, Changsha \\ 410008, Hunan, China \\ ${ }^{5}$ Department of Anesthesiology, Third Xiangya Hospital of Central South University, Changsha 410008, Hunan, \\ China
}

Correspondence to: Juanni Li; email: lijuanni2014@csu.edu.cn

Keywords: GSDM family, hepatocellular carcinoma, expression profiles, prognosis, immune infiltration

Received: September 2, $2021 \quad$ Accepted: October 28, 2021

Published: November 3, 2021

Copyright: (C) $2021 \mathrm{Hu}$ et al. This is an open access article distributed under the terms of the Creative Commons Attribution License (CC BY 3.0), which permits unrestricted use, distribution, and reproduction in any medium, provided the original author and source are credited.

\section{ABSTRACT}

Six Gasdermins (GSDM) family members participate in various biological processes especially pyroptosis, as well as in the initiation and development of many types of cancer. However, the systematic analysis of the GSDM family in hepatocellular carcinoma (HCC) is lacking. In this study, several bioinformatics databases were recruited to analyze the roles of the GSDMs in differential expression, prognostic correlation, functional enrichment exploration, immune modulation, genetic alterations, and methylated modification in patients with HCC. Consequently, the mRNA expression of all the six GSDMs was accordantly increased in HCC, while only the protein expressions of GSDMB, GSDMD, and GSDME were apparently increased in HCC tissue. The expression of all the GSDMs (except GSDMA) was significantly higher in tumor stage 1-3 subgroups, compared with that in normal subgroups. Higher GSDME expression was significantly associated with shorter overall survival (OS) and disease specific survival (DSS) in patients with HCC. GSDMD had the highest genetic alteration rate among the GSDMs. The three signal pathways which were most likely related to GSDMs-associated molecules were the cell adhesion, growth regulation, and hormone metabolic process. The majority of GSDMs members were positively correlated with the infiltration of B cells, neutrophils, and dendritic cells, however negatively correlated with macrophage. All of the six GSDM members showed remarkably decreased methylation levels in HCC tissues. In conclusion, the GSDM family (especially GSDME) had the potential to become essential biomarkers to better improve the diagnosis and prognosis of HCC, as well as provided insight for the development of therapeutic targets.

\section{INTRODUCTION}

Liver cancer is the leading cause of cancer-related deaths globally, with the foremost morbidity and incidence among all types of cancer. Hepatocellular carcinoma (HCC) as the most common subtype in liver cancer, is characterized by the insidious onset, high malignancy, and awfully poor clinical outcomes $[1,2]$.
It is reported that merely $30 \%$ of patients with $\mathrm{HCC}$ are at the early stage which is suitable for radical surgery. Moreover, the effectiveness of chemotherapeutic drugs, targeted drugs, and immunotherapeutic agents for advanced HCC remains limited [3, 4]. Hence exploring novel biomarkers and molecular targets is of great value for the development of HCC therapeutic strategy. 
Gasdermins (GSDM) family members are six poreforming effector proteins that were identified very recently, including GSDMA, GSDMB, GSDMC, GSDMD, GSDME (DFNA5), and PJVK (Pejvakin, DFNB59). All the six GSDMs share a highly conserved pore-forming domain which is responsible for the membrane permeabilization and cell pyroptosis [5-7]. Pyroptosis is a novel form of lytic programmed cell death with the characterization of pro-inflammation that is broadly involved in a variety of biological processes such as human development and immune response [810]. Besides, emerging researches have revealed the strong correlation between the dysregulation of GSDMs and the initiation and development of a various type of cancer [11]. For instance, a study demonstrated that GSDMB induced by lymphocyte-derived granzyme A (GZMA) could trigger the pore-forming activity and pyroptosis, thus promoting anti-tumor immunity [12]. In addition, rs8067378 polymorphism conspicuously increased the expression of GSDMB and the initiation of cervical squamous cell carcinomas [13]. Furthermore, GSDMC was proved to act as an oncogene in colorectal cancer based on the observation that silence of GSDMC remarkably decreased the proliferation of colorectal cancer cells [14]. GSDME was shown to play the role of a tumor suppressor through the mechanisms of pyroptosis activation and increased anti-tumor immunity [15]. Nevertheless, the roles of the six GSDM family members in HCC have not been comprehensively studied before.

Here, we systematically analyzed the GSDM family members in the aspects of the expression profiles, prognostic value, status of genetic alteration, functional enrichment analysis, immune cell infiltration, and methylation status by the usage of multiple public databases. We believed this study may extend the recognition of the role of GSDMs in HCC and provide trains of thought and clues for further mechanistic investigation.

\section{RESULTS}

\section{Aberrantly increased expression of GSDM family members in patients with $\mathrm{HCC}$}

UALCAN databases were enrolled to detect the mRNA expression of the GSDM family members in HCC. Notably, the mRNA expression of all the six GSDMs was accordantly higher in HCC tumor tissue compared with normal tissue (Figure 1A). Then the immunohistochemistry (IHC) staining which represented the protein expression of GSDMs were obtained through the Human Protein Atlas database (THPA) (Supplementary Figure 1), showing that the protein expressions of GSDMB, GSDMD, and GSDME were higher in HCC tissue compared with normal tissue, which is in accordance with the tendency of their mRNA expression. While the protein expressions of GSDMA and GSDMC could not be detected in IHC staining. A probable reason for this inconsistency maybe because of the low value of transcript per million (TPM) of GSDMA and GSDMC, which made their protein expression abundances relatively hard to be detected by IHC. No IHC data of PJVK was retrieved from the THPA database. In addition, the relative expression level within the GSDM family members are ranked as below from high to low: GSDMD, GSDMB, PJVK, GSDMA, GSDMC, and GSDME (Figure 1B).

\section{The association between GSDMs and the clinicopathological parameters in patients with HCC}

The tumor stage and tumor grades, the two important clinicopathological parameters were further analyzed in the context of GSDMs expression. The expression of all the six GSDMs (except GSDMA) was significantly higher in tumor stage 1-3 subgroups, compared with that in normal subgroups (Figure 2A). However, there was no difference when it came to tumor stage 4. Besides, the GSDME and PJVK expressions in tumor stage 4 were contrarily decreased compared to tumor stages 1 and 3. These results suggested that there might exist some mechanisms in advanced stages of HCC which hampered the increased expression of GSDMs. As for the tumor grade, GSDMD and GSDME expression increased gradually and significantly from grade 1 to grade 4 . For the case of GSDMA, GSDMB, GSDMC, and PJVK, this trend of increased expression still existed but lack the statistic difference (Figure 2B). These data indicated that tumor cell differentiation may to some extent reflected the GSDMs.

\section{The prognostic role of GSDMs in patients with $\mathrm{HCC}$}

Overall survival (OS) was used as the primary endpoint to assess the prognostic role of each GSDM family member, data returned from Kaplan-Meier plotter and UALCAN databases gave consistent results, namely only high GSDME expression was significantly associated with shorter OS in patients with HCC (Figure 3). To further verify this result, the disease specific survival (DSS) of subgroups stratified according to GSDMs was analyzed. As a consequence, high expression of GSDME was correlated with poor DSS (Supplementary Figure 2). There was no significant difference between the other GSDMs and OS/DSS, despite their obviously up-regulated expression in $\mathrm{HCC}$.

\section{Analysis of genetic alteration and homology in the GSDM family in patients with $\mathrm{HCC}$}

The profiles of genetic alterations of each GSDM member were shown in Figure 4 with the application 
of the TCGA database and the cBioPortal online tool. On the whole, GSDM family genes are altered in 170 $(47 \%)$ of 360 enrolled HCC patients. GSDMD had the highest genetic alteration rate $(30 \%)$ among the GSDM family members, then the genetic alteration rate ranked from high to low as below: GSDMC (26\%), PJVK (7\%), GSDME (6\%), GSDMB (4\%) and GSDMA (3\%) (Figure 4A). About the types of genetic alteration of GSDM members, amplification and mRNA high were the two main alteration types. The missense mutation, deep deletion, inframe mutation, and splice mutation happened rarely in GSDMs. Next, the homologous analysis inside the GSDM family members was onset, giving the result that GSDMC had a relatively strong correlation with GSDMB $(\mathrm{R}=0.64)$ and GSDMA $(\mathrm{R}=0.34)$, PJVK was found to be more similar with GSDMA $(\mathrm{R}=0.34)$ (Figure 4B).

\section{Screening of GSDMs associated molecules and functional enrichment analysis}

cBioPortal and Cytoscape were used to screen out the top 168 genes which were co-expressed and associated with the GSDMs, then the protein-protein interaction (PPI) network was built base on it. Consequently, molecules like MMP9, CYP3A4, AFP, IGF2, G6PC, $\mathrm{AR}$, and PPARGC1A had the highest possibility to cooperate with GSDMs, thus contributed to the initiation and progression of HCC (Figure 5A). To better understanding the associated function of GSDMs in HCC, the functional enrichment analysis was performed based on the 168 GSDM-correlated genes by using Gene Ontology (GO) annotation from the WebGestalt database. As presented in Figure 5B, the top-ranked biological processes regarding GSDMs were metabolic process, biological regulation, response to
A

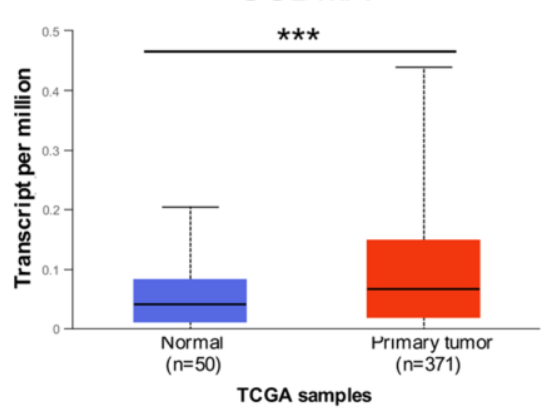

GSDMD

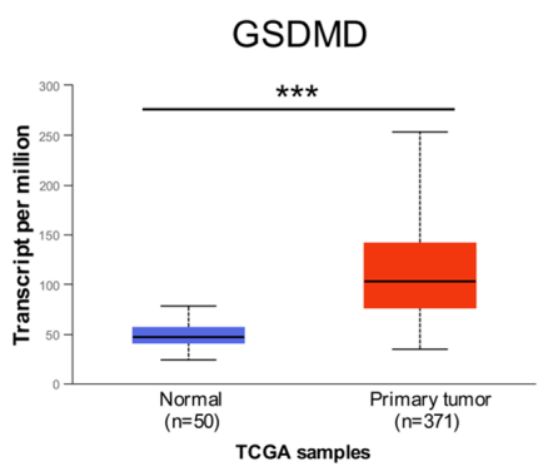

B
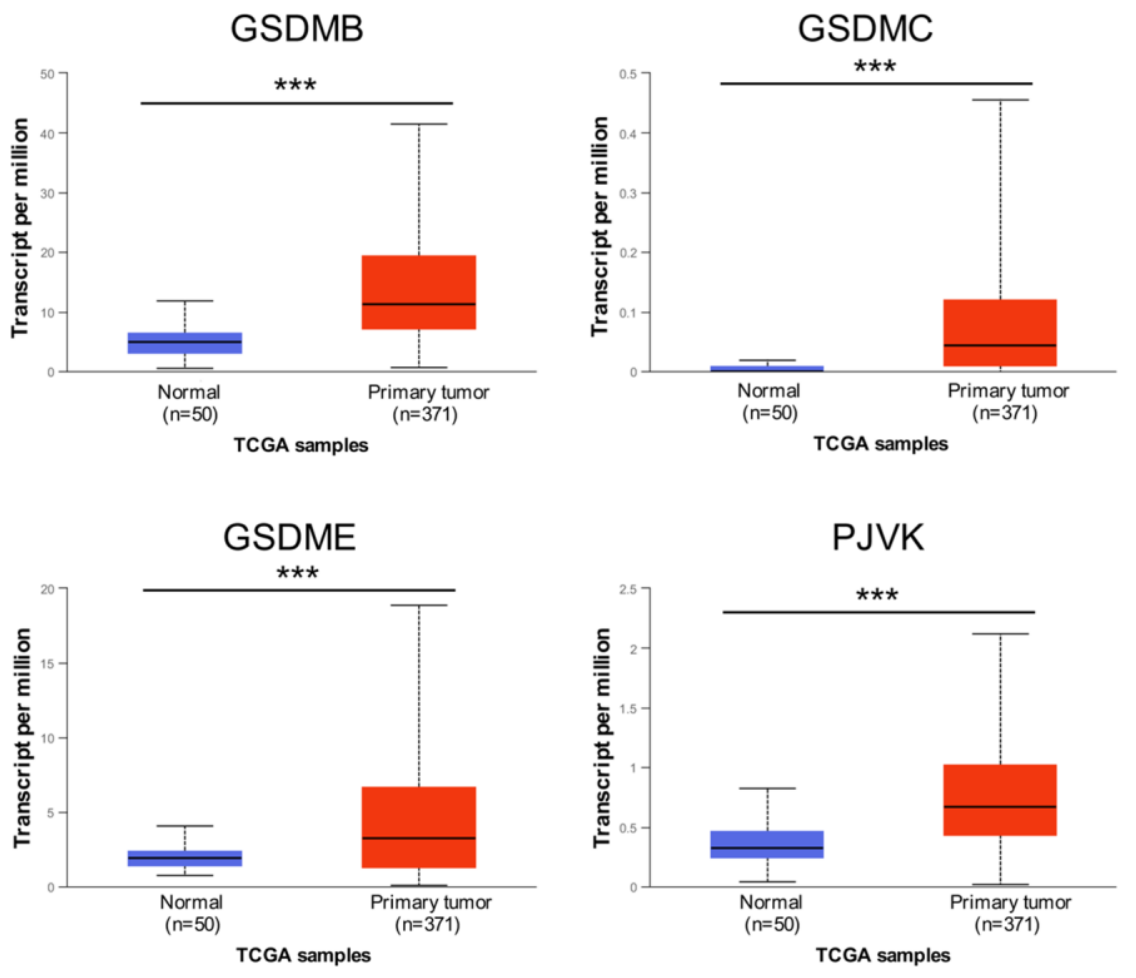

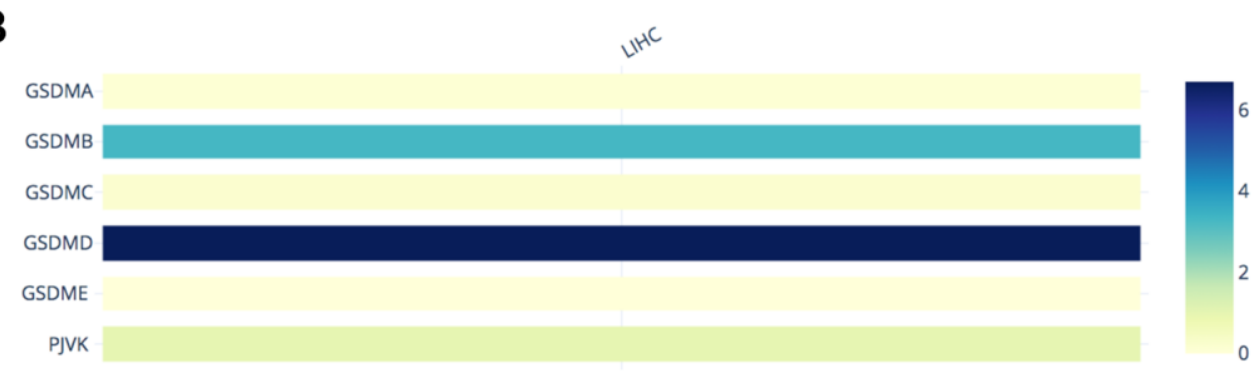

Figure 1. The mRNA expression levels of six GSDM family members in HCC. (A) GSDMs mRNA expression profiles were collected from the UALCAN database. (B) The relative mRNA expression level of individual GSDM family members in $\mathrm{HCC}^{* * *} p<0.001$. 
stimulus, multicellular organismal process, and cell communication. Moreover, the most highly enriched cellular components associated with GSDMs were membrane, endomembrane system, nucleus, and extracellular space. As for the molecular functions related to GSDMs, the protein binding, ion binding, nucleic acid binding, and hydrolase activity appeared on the list (Figure 5B). Furthermore, the Kyoto Encyclopedia of Genes and Genomes (KEGG) pathway analysis demonstrated nine potential signal pathways which were most likely related to GSDMs-associated molecules. The top three pathways were the cell
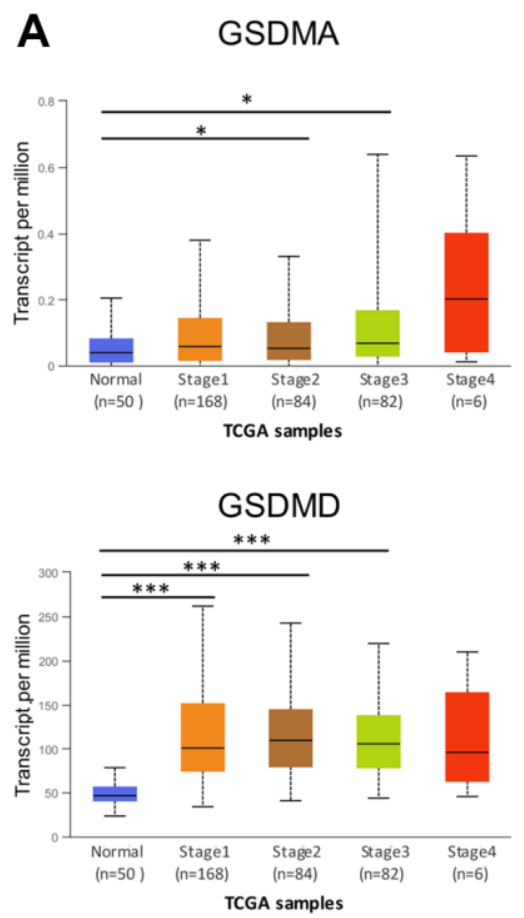

B

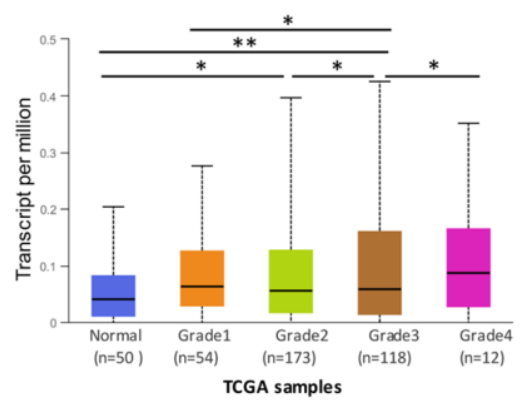

GSDMD

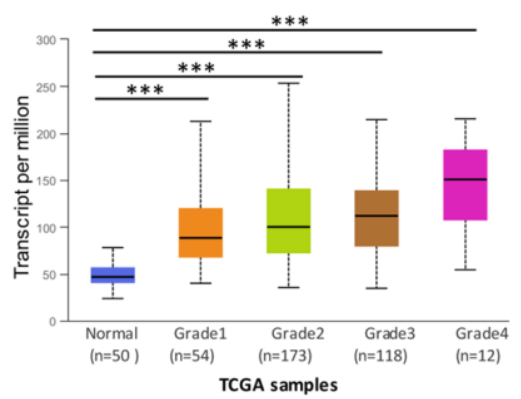

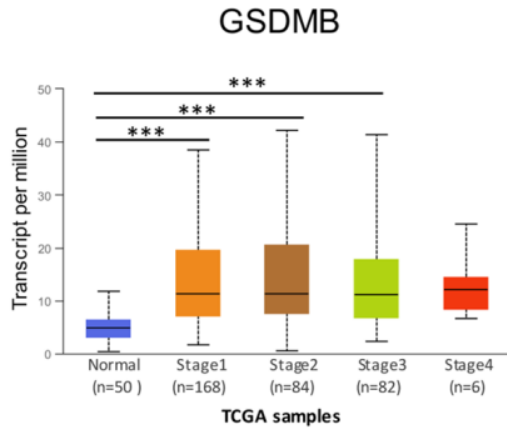
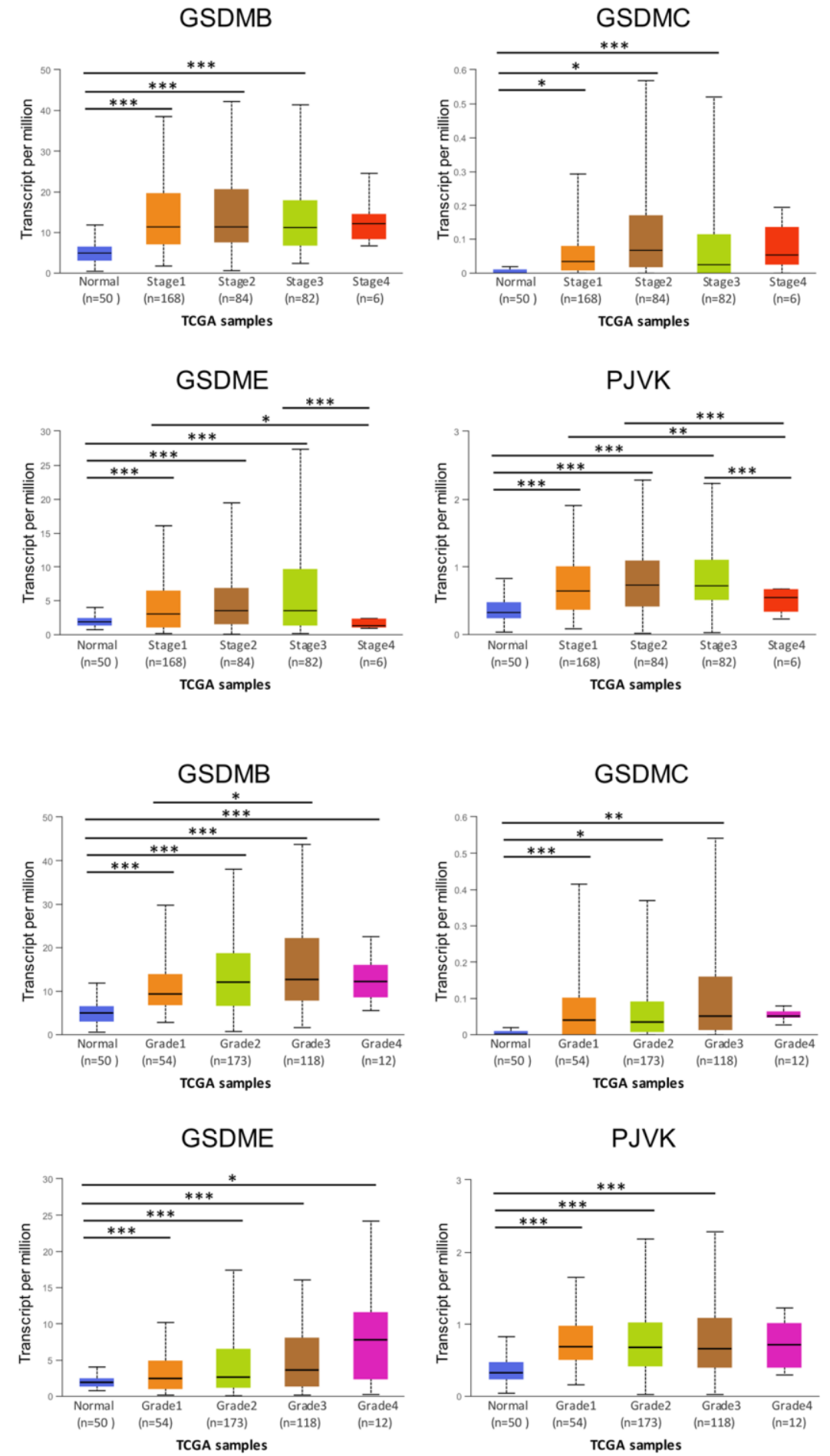

Figure 2. Association of GSDMs mRNA expression levels with clinical pathology from UALCAN. (A) Relationships between GSDMs transcript levels and individual cancer stages of HCC. (B) Relationships between GSDMs transcript levels and tumor grades of HCC. ${ }^{*} p<0.05,{ }^{* *} p<0.01,{ }^{* * *} p<0.001$. 
adhesion pathway, growth regulation pathway and pathway accounted for hormone metabolic process (Figure 5C).

\section{The correlation of immune cell infiltration with GSDMs expression}

The various types of immune cells which infiltrated around tumor tissue were essential components of the tumor microenvironment [16]. Studies have shown that tumor biology behaviors including tumorigenesis, progression, and metastasis could be significantly affected by infiltrated immune cells $[17,18]$. To explore if there was any relationship between GSDMs and immune cell infiltration, the TIMER 2.0 database was utilized in this section. As the results, GSDMA was positively correlated with infiltration of CD8+ T cell $($ Rho $=0.301, P=1.14 \mathrm{e}-08)$, B cell $(R h o=0.244, P=$
A

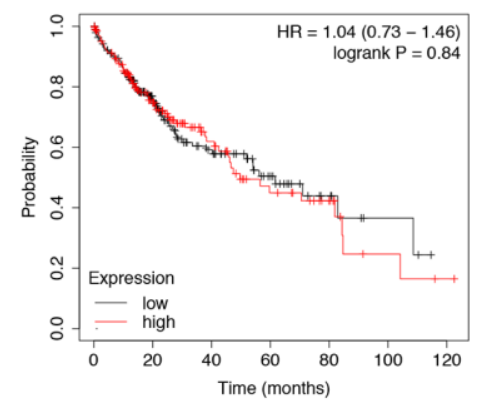

GSDMD

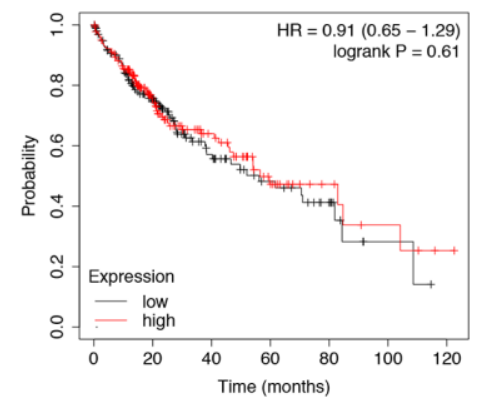

B

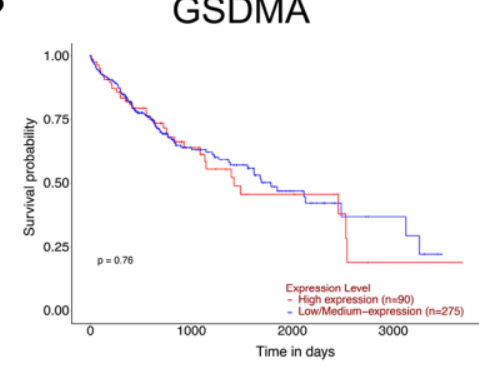

GSDMD

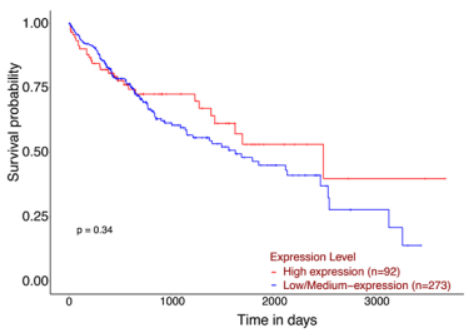

GSDMB

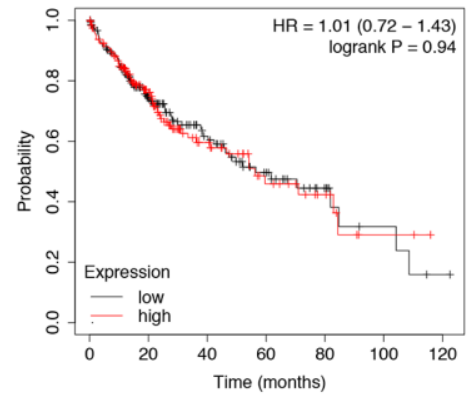

GSDME

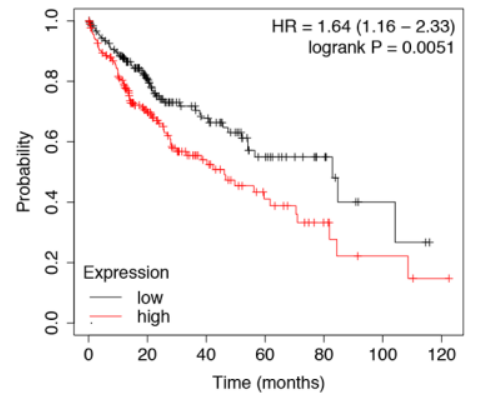

GSDMB

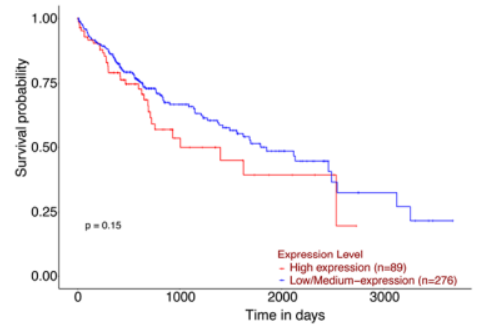

GSDME

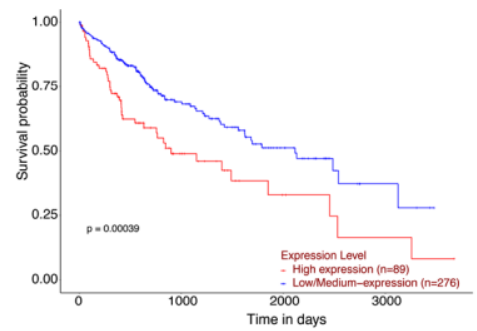

GSDMC

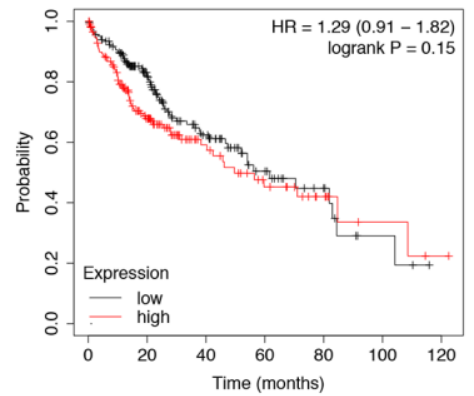

PJVK

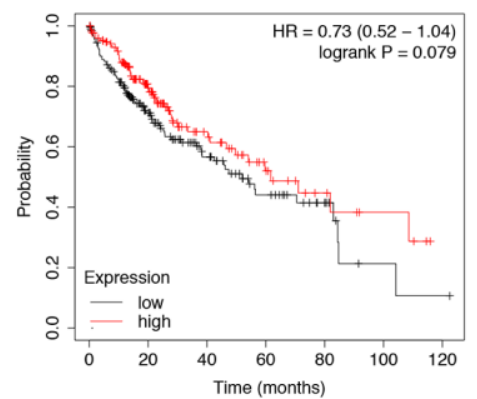

GSDMC

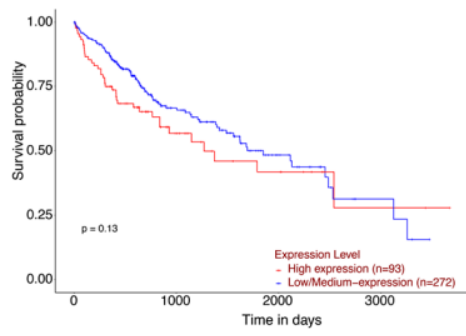

PJVK

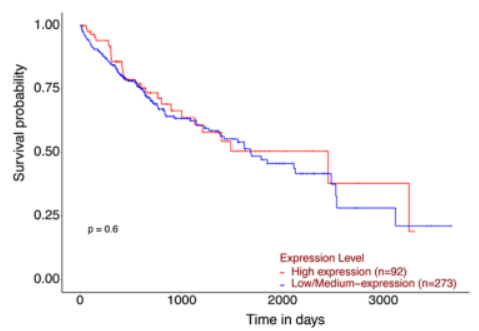

Figure 3. Prognostic value of GSDMs mRNA expression levels in HCC. (A) Relationships between GSDMs transcript levels and overall survival (OS) of HCC patients were conducted using Kaplan-Meier plotter. (B) Relationships between GSDMs transcript levels and overall survival (OS) of HCC patients were analyzed through the UALCAN database. 
4.40e-06), neutrophil (Rho $=0.186, P=5.24 \mathrm{e}-04)$, and dendritic cell $(R h o=0.482, P=1.73 \mathrm{e}-21)$, while was negatively correlated with infiltration of macrophage (Rho $=-0.192, P=3.37 \mathrm{e}-04)$. GSDMB was only negatively correlated with CD4+ T cell infiltration $($ Rho $=-0.134, P=1.26 \mathrm{e}-02)$. GSDMD was only positively correlated with infiltration of $\mathrm{B}$ cell $(R h o=$ $0.181, P=7.32 \mathrm{e}-04)$ and dendritic cell $(R h o=0.143, P$ $=8.00 \mathrm{e}-03)$. The profiles of immune cell infiltration in the cases of GSDMC and GSDME exhibited a certain degree of similarity with that in GSDMA. PJVK was found to have negative correlation with $\mathrm{CD} 8+\mathrm{T}$ cell infiltration ( $R h o=-0.106, P=4.93 \mathrm{e}-02)$ and positively correlation with neutrophil $(R h o=0.128, P=1.71 \mathrm{e}$ 02) (Figure 6).

\section{DNA methylation levels of the GSDMs in HCC patients}

DNA methylation is a crucial part of the posttranscriptional modification that can negatively regulate gene expression, thereby get involved in the initiation and progression of cancer $[19,20]$. We utilized the
DiseaseMeth database here to further investigated the DNA methylation level of each GSDM family member in HCC tissues and made the comparison with that in normal liver tissues. As presented in Supplementary Figure 3, all of the six GSDM members showed remarkably decreased methylation levels in HCC tissues, suggesting that DNA methylation might be the partial mechanism underneath that made the GSDMs mRNA expression increased. Further mechanistic investigation of GSDMs methylation may bring benefits for the treatment of HCC patients.

\section{DISCUSSION}

Pyroptosis is a recently identified form of programmed cell death that is mediated by GSDM family members $[5,21]$. A variety of inflammation and immune responses happen concomitantly alongside the pyroptosis [22]. Increasing evidence these days indicated the indispensable role of GSDMs and pyroptosis in various cancer, making GSDM-mediated pyroptosis a novel and prospective research direction $[23,24]$. For example, the caspase-3/GSDME axis

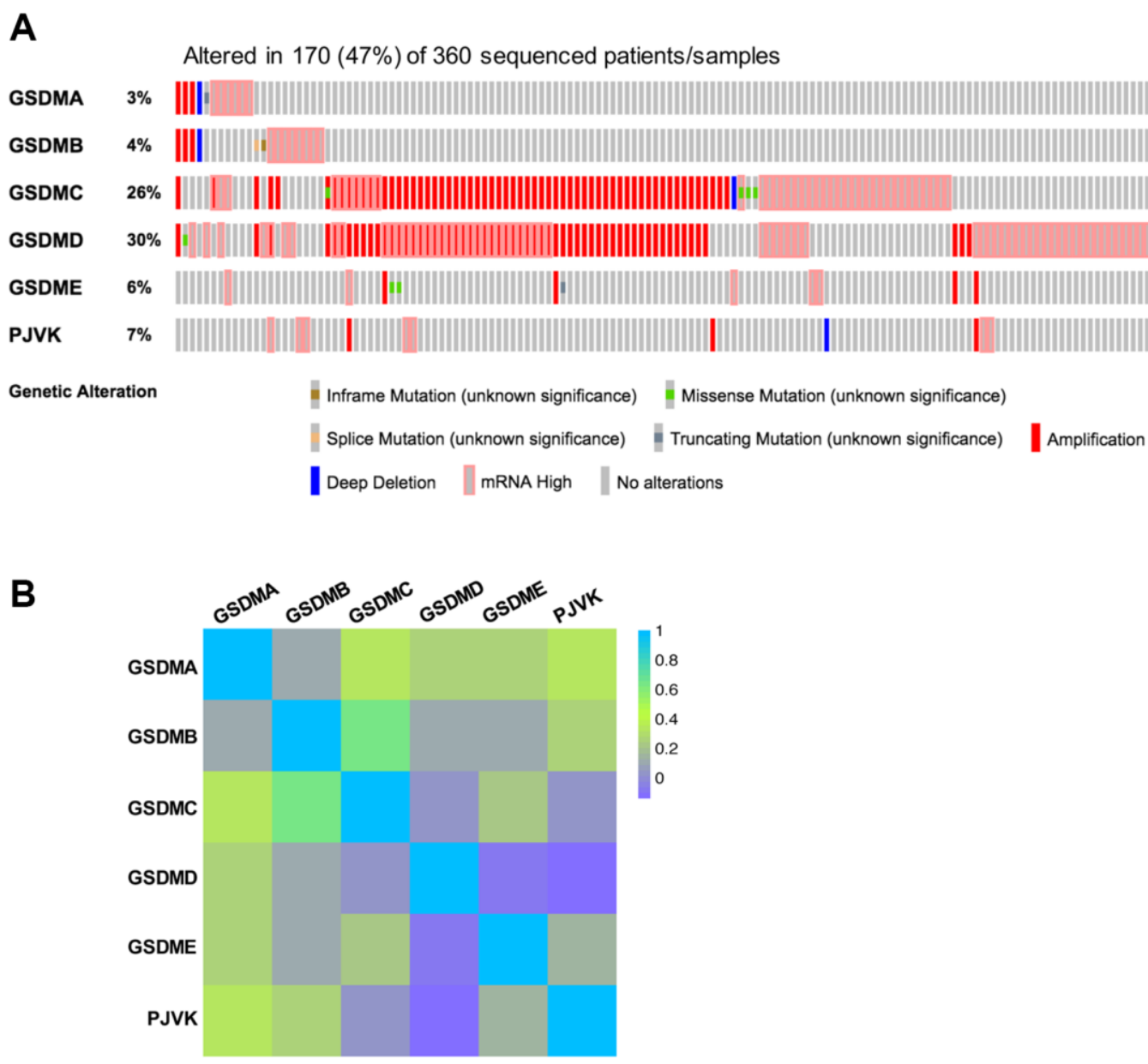

Figure 4. Genetic alterations and correlation analysis of six GSDM family members in HCC. (A) Genetic alteration profiles of six GSDM family members in HCC (cBioPortal). (B) Correlation between six GSDM family members in HCC by using GEPIA2. 
could activate pyroptosis through the ROS/JNK pathway in breast cancer [25]. Moreover, it was reported that GSDMC inhibited the TGF $\beta$ R2 activation, thereby acted as an oncogene and promoted the proliferation of colorectal cancer cells [14]. The above researches indicated that each GSDMs member has its particular functions in different cancer types, the same GSDMs molecule can either act as an oncogene or tumor-suppressive gene based on the tumor heterogeneity.

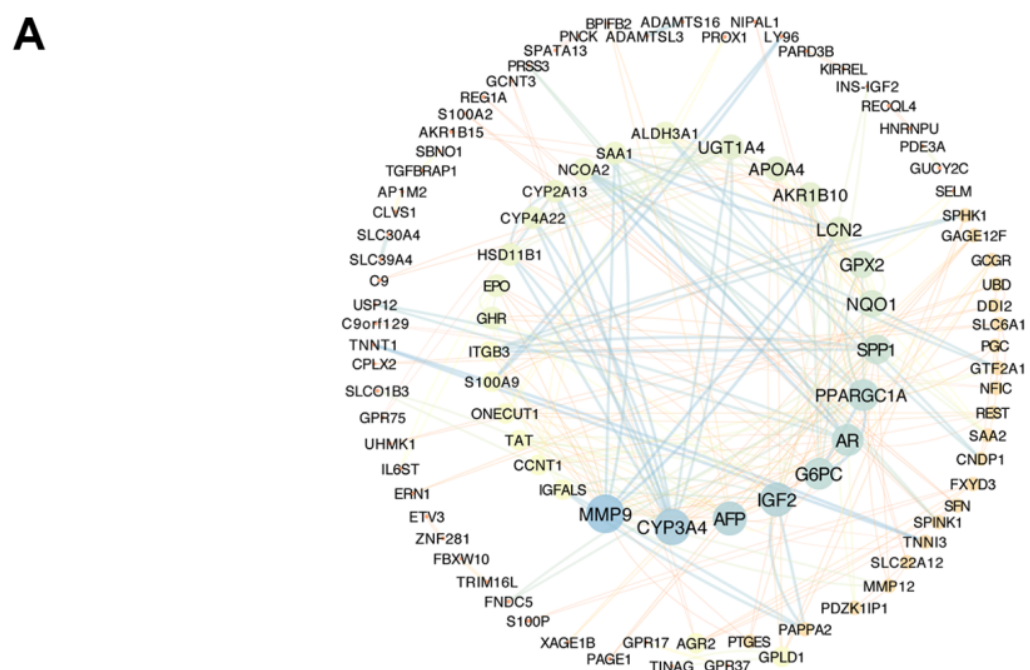

B
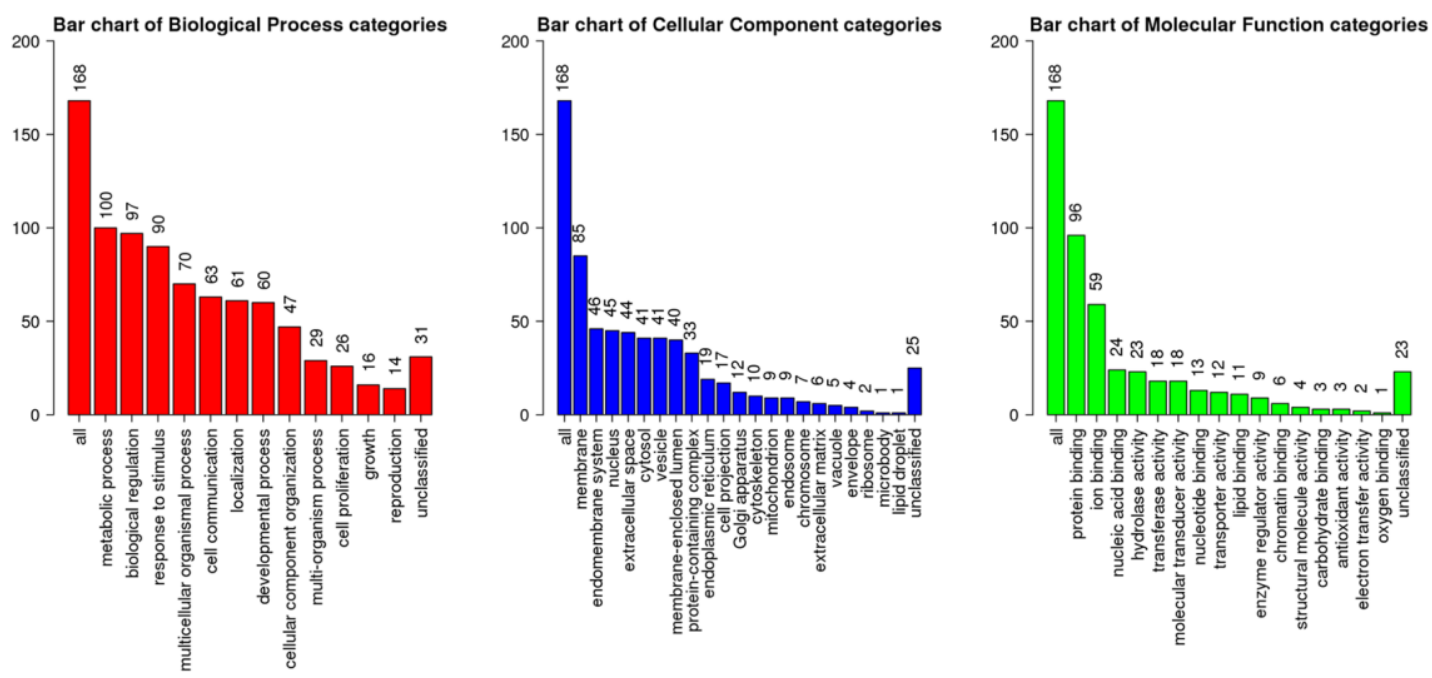

C $={ }^{F D R}<0.05 \quad=F D R>0.05$

cell-cell adhesion via plasma-membrane

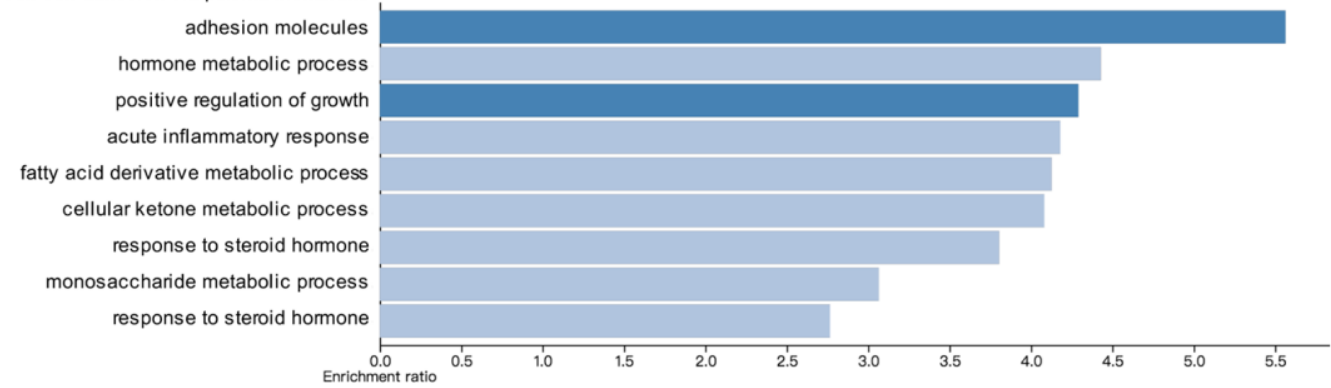

Figure 5. Predicted functions and pathways of GSDMs and GSDM-associated co-expressed molecules in HCC. (A) 168 GSDMassociated co-expressed molecules which were most frequently altered in HCC were identified by using cBioPortal, and protein-protein interaction (PPI) network was then conducted by Cytoscape. (B) Gene Ontology (GO) functional enrichment analysis of GSDM-associated co-expressed molecules was conducted by WebGestalt. (C) Kyoto Encyclopedia of Genes and Genome (KEGG) pathway analysis of GSDMassociated co-expressed molecules was conducted by WebGestalt. 
As far as our concern, there is no systematic analysis aiming at the role of GSDM family members in HCC. Hence in the present study, we first explored the differential mRNA expression of each GSDM family member in HCC tissues. We found that all the mRNA expressions of the six GSDM members were significantly increased in HCC tissues, suggesting their potential to act as oncogenes. This high consistency of expression tendency of the GSDM family highlighted the potential role of GSDM-associated pathway and function (such as pyroptosis) in HCC. However, in terms of the protein expression level, only GSDMB, GSDMD, and GSDME gave accordant results, which were highly expressed in HCC tissues.

Then the prognostic assessment based on the expression of GSDMs was performed to further test if GSDMB, GSDMD, and GSDME are competent to be oncogenes.
Only GSDME was proved to have prognostic value for HCC patients because the high GSDME group had shorter OS and DSS. These data collectively draw our interest in the GSDME and made GSDME a potential biomarker that could predict the clinical outcome of $\mathrm{HCC}$, as well as a therapeutic target for drug research and development. To our knowledge, there were many studies that echo our findings. For instance, GSDME was reported to be activated by miltirone, thereby induced pyroptosis and inhibited the tumor growth in HCC [26]. Furthermore, evidence proved that cisplatininduced a high degree of pyroptosis in lung cancer cells through the caspase-3/GSDME pathway [27]. In another published paper, GSDME knockout in colorectal mice model showed decreased pyroptosis degree, attenuated tumor size, and number. Such antitumor effect was proved to be achieved by ERK1/ 2-dependent releasing of HMGB1 [28]. Therefore, we

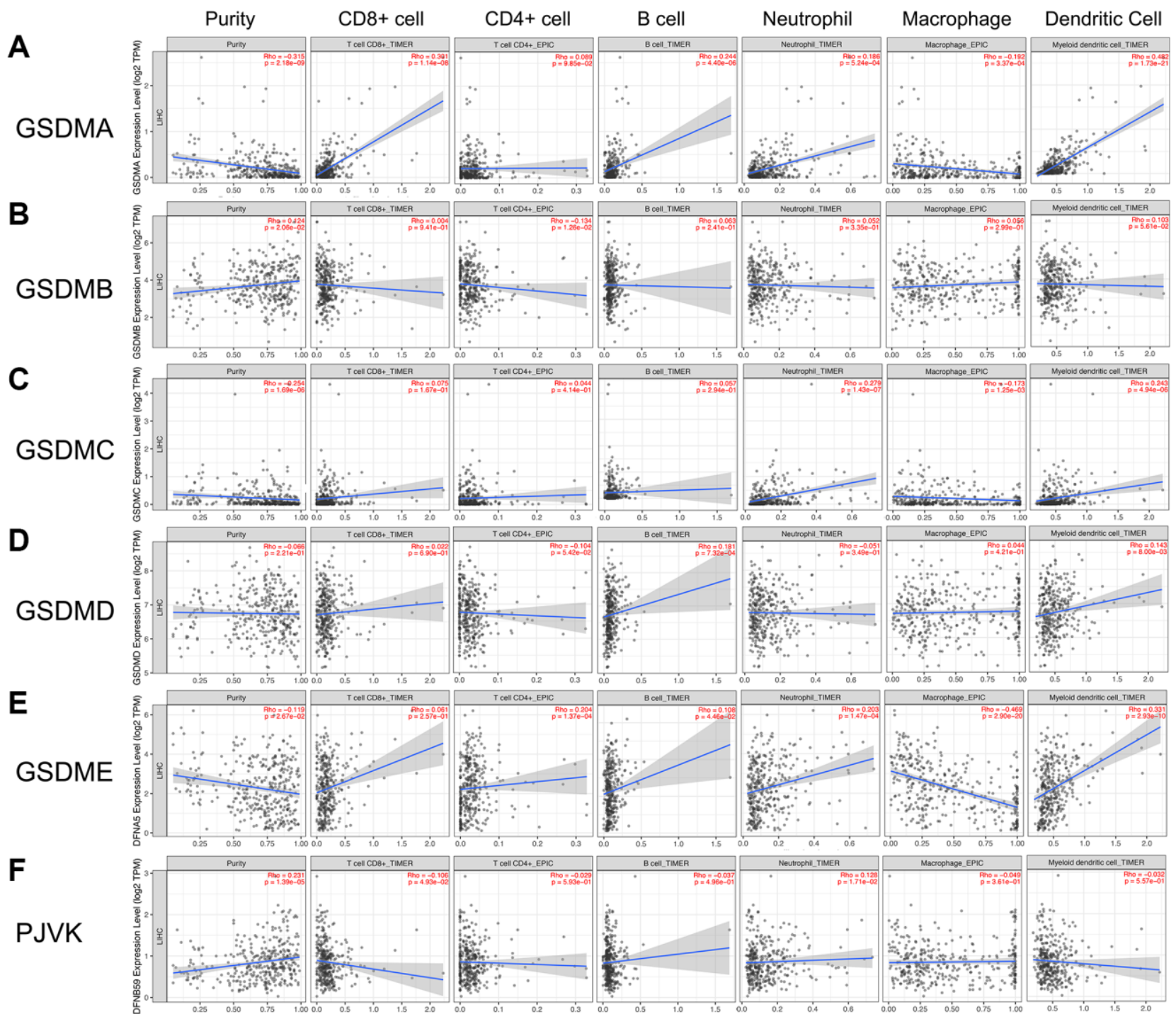

Figure 6. Association of GSDMs mRNA expression levels with immune cell infiltration. The effects of (A) GSDMA, (B) GSDMB, (C) GSDMC, (D) GSDMD, (E) GSDME, and (F) PJVK on the immune cell infiltration were evaluated by the TIMER2.0 database. 
believed that GSDME had the potential to become a novel biomarker and therapeutic target on the premise of firm evidence of experiments and a clear illustration of the mechanism.

Our study is the first to show that GSDMs members shared the high expression profiles from tumor stage 1 to stage 3 in HCC, however, their expressions decreased to the normal levels for the HCC patients at stage 4. We speculated that although the GSDMs were involved in the progression of $\mathrm{HCC}$, the poor general situation and decompensated status in the end stage of HCC might interfere with the increased expression of GSDMs.

Then the molecules such as MMP9 and AR were filtered as the co-expressed genes which were mostly related to GSDMs through the interactive network analysis. In addition, functional enrichment analysis in $\mathrm{HCC}$ revealed that the cell adhesion and the hormone metabolic process were the most relevant pathway in which GSDMs were involved. Cell adhesion is a key factor that participates in multi-steps of tumor progression such as tumor invasion, metastasis, and epithelial-mesenchymal transition [29]. HCC cells adhesion was reported to promote metastasis via the SMAD3 pathway in an exosome-dependent way [30]. Numerous kinds of hormone metabolisms are taken place in the liver - the hotbed that breeds the HCC. Therefore, the tumorigenesis and progression of HCC are indispensably influenced by hormones including AR. Recently an article uncovered that the mechanism of olaparib and enzalutamide in suppressing $\mathrm{HCC}$ progression is partially owing to the AR-mediated BRCA1 signaling pathway $[31,32]$. Another study also demonstrated that AR dramatically reduced the HCC invasion and migration by targeting the miR-325/ACP5 pathway [33]. By king both our findings and published studies mentioned above into account, we believe further investigations along the direction of GSDMs, adhesion, and hormone metabolism were of great expectation.

Immune cell infiltration has been recognized these days as a pivotal parameter that is closely correlated with the progression and recurrence of tumors, the clinical outcome, and the efficacy of immunotherapy $[34,35]$. Besides, infiltrated immune cells such as macrophage and CD8+T cells can be activated by GSDMs-mediated pyroptosis, thereby promote phagocytosis and antitumor immunity [15]. We found that there was a specific profile of immune cell infiltration according to the GSDMs in HCC. The majority of GSDMs members were positively correlated with the infiltration of $\mathrm{B}$ cells, neutrophils, and dendritic cells, however negatively correlated with macrophage. These data suggested that GSDMs-mediated pyroptosis might play crucial roles in anti-tumor immunity by affecting the profiles of immune cell infiltration.

As a key component of post-transcriptional modification, DNA methylation has been intensively reported to be involved in the regulation of cancerassociated genes [36, 37]. In our study, we found that the methylation level of all the GSDMs members is significantly reduced in $\mathrm{HCC}$ tissues, which puts us in mind of the increased expression of GSDMs in HCC tissues. These data highlighted the importance of DNA methylation in the GSDM family and clarified the direction of mechanism research towards DNA methylation was correct and worthy.

\section{CONCLUSIONS}

In summary, the expression and function profiles of the GSDM family were disordered in HCC. The GSDM family (especially GSDME) had the potential to become essential biomarkers to better improve the diagnosis and prognosis of HCC, as well as provided insight for the development of therapeutic targets.

\section{MATERIALS AND METHODS}

\section{UALCAN}

The UALCAN database is a comprehensive and interactive web tool used for analyzing cancer data from OMICS (including TCGA, MET500, and CPTAC databases) [38]. UALCAN database was applied in this study to investigate the mRNA expression levels of GSDM family members in HCC. The mRNA expression of the GSDM members based on the HCC stage and HCC grade was further analyzed through UALCAN. In addition, the prognosis value of HCC patients based on GSDM expression was also analyzed using this database. The $p$-value equals to 0.05 was set as the cutoff with statistical significance. The databases used in the present study were summarized in Supplementary Table 1.

\section{The human protein atlas}

The Human Protein Atlas is an online database that contains human proteins data derived from cells, tissues, and organs [39]. We employed this database to extract the immunohistochemistry results of each GSDM family member in HCC and normal liver tissues.

\section{Kaplan-Meier plotter}

Kaplan-Meier Plotter is a public database that allows users to analyze the prognostic role of a mass of genes on 
survival in various types of cancer [40-42]. Here we used Kaplan-Meier Plotter to explore the correlation with GSDM family members of the overall survival and disease specific survival in patients with HCC. The $p$-value equals to 0.05 was set as the cutoff with statistical significance.

\section{cBioPortal}

cBioPortal is a public web application designed for better utilization of genomics and clinical data in cancer researches $[43,44]$. We use cBioPortal to retrieve a dataset containing 360 patients with HCC (TCGA, Firehose Legacy), then the co-expression and gene alteration analysis of GSDM family members were performed through $\mathrm{cBioPortal}$.

\section{Cytoscape and WebGestalt}

We used Cytoscape application to process the data of 168 co-expression genes of GSDMs which were obtained from the cBioPortal database (these gene names could be found in Supplementary Table 2) [45]. WebGestalt is a web tool for functional enrichment analysis based on gene sets in various biological contexts [46]. WebGestalt is adopted in this study to conduct the Gene Ontology (GO) analysis and the Kyoto Encyclopedia of Genes and Genomes (KEGG) analysis.

\section{TIMER 2.0}

TIMER 2.0 is an open-access tool that allows users to make an assessment of immune cell infiltration based on the expression of specific genes in 32 types of cancer [47]. The module named "immune association" in this web tool was adopted to acquire the scatterplots that illustrate the correlation of GSDMs with different types of infiltrated immune cells (dendritic cells, macrophages, CD4+ T cells, CD8+ T cells, B cells, and neutrophils).

\section{DiseaseMeth2.0}

DiseaseMeth2.0 is a professional online resource offering DNA methylation information in a variety of human diseases including cancer [48, 49]. The methylation status of GSDM family members in HCC and normal liver tissues were retrieved from this public resource. The $p$-value equals to 0.05 was set as the cutoff with statistical significance.

\section{Ethical statement}

The authors are accountable for all aspects of the work in ensuring that questions related to the accuracy or integrity of any part of the work are appropriately investigated and resolved. None of the data have been previously published or appeared in copyrighted form elsewhere, and no previously published or unpublished data were cited in this paper. No ethics approval was required for this bioinformatics article, as it did not involve patients or patient data.

\section{AUTHOR CONTRIBUTIONS}

Conception and design: $\mathrm{J} \mathrm{Li}$ and $\mathrm{K} \mathrm{Hu}$. Writing, review, and/or revision of the manuscript: $\mathrm{K} \mathrm{Hu}, \mathrm{J} \mathrm{Li}$, L Zhou and $\mathrm{L}$ Yao. Administrative, technical, or material support: $\mathrm{Z} \mathrm{Xu}$ and $\mathrm{Y}$ Yan. All authors approved the final version of the manuscript.

\section{CONFLICTS OF INTEREST}

The authors declare no conflicts of interest related to this study.

\section{FUNDING}

This study is supported by grants from National Natural Science Foundation of China (82103300, 82102743), Youth Science Foundation of Xiangya Hospital (2020Q07), Natural Science Foundation of Hunan Province (2019JJ50932, 2020JJ5934), China Postdoctoral Science Foundation (2020M672521).

\section{REFERENCES}

1. Bousali M, Papatheodoridis G, Paraskevis D, Karamitros T. Hepatitis B Virus DNA Integration, Chronic Infections and Hepatocellular Carcinoma. Microorganisms. 2021; 9:1787. https://doi.org/10.3390/microorganisms9081787 PMID: $\underline{34442866}$

2. Ioannou GN. Epidemiology and risk-stratification of NAFLD-associated HCC. J Hepatol. 2021. [Epub ahead of print]. https://doi.org/10.1016/j.jhep.2021.08.012 PMID: 34453963

3. Ilyas FZ, Beane JD, Pawlik TM. The State of Immunotherapy in Hepatobiliary Cancers. Cells. 2021; 10:2096. https://doi.org/10.3390/cells10082096 PMID:34440865

4. Fulgenzi CAM, Talbot $T$, Murray SM, Silletta $M$, Vincenzi B, Cortellini A, Pinato DJ. Immunotherapy in Hepatocellular Carcinoma. Curr Treat Options Oncol. 2021; 22:87. https://doi.org/10.1007/s11864-021-00886-5 PMID:34424422 
5. Ryder $\mathrm{CB}$, Kondolf $\mathrm{HC}$, O'Keefe ME, Zhou B, Abbott DW. Chemical Modulation of Gasdermin-Mediated Pyroptosis and Therapeutic Potential. J Mol Biol. 2021. [Epub ahead of print].

https://doi.org/10.1016/j.jmb.2021.167183

PMID:34358546

6. De Schutter E, Roelandt R, Riquet FB, Van Camp G, Wullaert A, Vandenabeele P. Punching Holes in Cellular Membranes: Biology and Evolution of Gasdermins. Trends Cell Biol. 2021; 31:500-13.

https://doi.org/10.1016/i.tcb.2021.03.004 PMID: $\underline{3771452}$

7. Zheng Z, Deng W, Lou X, Bai Y, Wang J, Zeng H, Gong $S$, Liu X. Gasdermins: pore-forming activities and beyond. Acta Biochim Biophys Sin (Shanghai). 2020; 52:467-74.

https://doi.org/10.1093/abbs/gmaa016 PMID: $\underline{32294153}$

8. Loveless R, Bloomquist R, Teng Y. Pyroptosis at the forefront of anticancer immunity. J Exp Clin Cancer Res. 2021; 40:264. https://doi.org/10.1186/s13046-021-02065-8 PMID:34429144

9. Wang R, Wang Y, Hu L, Lu Z, Wang X. Inhibition of complement $\mathrm{C} 5 \mathrm{a}$ receptor protects lung cells and tissues against lipopolysaccharide-induced injury via blocking pyroptosis. Aging (Albany NY). 2021; 13:8588-98.

https://doi.org/10.18632/aging.202671 PMID: $\underline{3714207}$

10. Li L, Jiang M, Qi L, Wu Y, Song D, Gan J, Li Y, Bai Y. Pyroptosis, a new bridge to tumor immunity. Cancer Sci. 2021; 112:3979-94. https://doi.org/10.1111/cas.15059 PMID:34252266

11. Li L, Li Y, Bai Y. Role of GSDMB in Pyroptosis and Cancer. Cancer Manag Res. 2020; 12:3033-43. https://doi.org/10.2147/CMAR.S246948 PMID:32431546

12. Zhou Z, He H, Wang K, Shi X, Wang Y, Su Y, Wang Y, Li D, Liu W, Zhang Y, Shen L, Han W, Shen L, et al. Granzyme A from cytotoxic lymphocytes cleaves GSDMB to trigger pyroptosis in target cells. Science. 2020; 368:eaaz7548. https://doi.org/10.1126/science.aaz7548 PMID:32299851

13. Lutkowska A, Roszak A, Lianeri M, Sowińska A, Sotiri E, Jagodziński PP. Analysis of rs 8067378 Polymorphism in the Risk of Uterine Cervical Cancer from a Polish Population and its Impact on Gasdermin B Expression. Mol Diagn Ther. 2017; 21:199-207. https://doi.org/10.1007/s40291-017-0256-1 PMID:28120299
14. Miguchi $M$, Hinoi $T$, Shimomura $M$, Adachi $T$, Saito $Y$, Niitsu $H$, Kochi $M$, Sada $H$, Sotomaru $Y$, Ikenoue $T$, Shigeyasu K, Tanakaya K, Kitadai Y, et al. Gasdermin C Is Upregulated by Inactivation of Transforming Growth Factor $\beta$ Receptor Type II in the Presence of Mutated Apc, Promoting Colorectal Cancer Proliferation. PLoS One. 2016; 11:e0166422. https://doi.org/10.1371/journal.pone.0166422 PMID:27835699

15. Zhang Z, Zhang $Y$, Xia S, Kong $Q$, Li S, Liu X, Junqueira C, Meza-Sosa KF, Mok TMY, Ansara J, Sengupta S, Yao $\mathrm{Y}, \mathrm{Wu} \mathrm{H}$, Lieberman J. Gasdermin E suppresses tumour growth by activating anti-tumour immunity. Nature. 2020; 579:415-20.

https://doi.org/10.1038/s41586-020-2071-9 PMID:32188940

16. Gajewski TF, Schreiber H, Fu YX. Innate and adaptive immune cells in the tumor microenvironment. Nat Immunol. 2013; 14:1014-22.

https://doi.org/10.1038/ni.2703

PMID:24048123

17. Huang Y, Kim BYS, Chan CK, Hahn SM, Weissman IL, Jiang W. Improving immune-vascular crosstalk for cancer immunotherapy. Nat Rev Immunol. 2018; 18:195-203.

https://doi.org/10.1038/nri.2017.145 PMID:29332937

18. Hinshaw DC, Shevde LA. The Tumor Microenvironment Innately Modulates Cancer Progression. Cancer Res. 2019; 79:4557-66. https://doi.org/10.1158/0008-5472.CAN-18-3962 PMID:31350295

19. Casalino L, Verde P. Multifaceted Roles of DNA Methylation in Neoplastic Transformation, from Tumor Suppressors to EMT and Metastasis. Genes (Basel). 2020; 11:922.

https://doi.org/10.3390/genes11080922 PMID: $\underline{32806509}$

20. Usui G, Matsusaka K, Mano Y, Urabe M, Funata S, Fukayama M, Ushiku T, Kaneda A. DNA Methylation and Genetic Aberrations in Gastric Cancer. Digestion. 2021; 102:25-32. https://doi.org/10.1159/000511243 PMID:33070127

21. Hu JJ, Liu X, Xia S, Zhang Z, Zhang Y, Zhao J, Ruan J, Luo $X$, Lou $X$, Bai $Y$, Wang J, Hollingsworth LR, Magupalli VG, et al. FDA-approved disulfiram inhibits pyroptosis by blocking gasdermin $\mathrm{D}$ pore formation. Nat Immunol. 2020; 21:736-45. https://doi.org/10.1038/s41590-020-0669-6 PMID:32367036

22. Li Z, Zhu J, Wang Y. ADAR3 alleviated inflammation and pyroptosis of neuropathic pain by targeting 
NLRP3 in chronic constriction injury mice. Gene. 2021; 805:145909.

https://doi.org/10.1016/j.gene.2021.145909

PMID: $\underline{34419568}$

23. Ruan J. Structural Insight of Gasdermin Family Driving Pyroptotic Cell Death. Adv Exp Med Biol. 2019; 1172:189-205.

https://doi.org/10.1007/978-981-13-9367-9 9 PMID:31628657

24. Jiang S, Gu H, Zhao Y, Sun L. Teleost Gasdermin E Is Cleaved by Caspase 1, 3, and 7 and Induces Pyroptosis. J Immunol. 2019; 203:1369-82. https://doi.org/10.4049/jimmunol.1900383 PMID:31391231

25. Zhang Z, Zhang H, Li D, Zhou X, Qin Q, Zhang Q. Caspase-3-mediated GSDME induced Pyroptosis in breast cancer cells through the ROS/JNK signalling pathway. J Cell Mol Med. 2021; 25:8159-68.

https://doi.org/10.1111/jcmm.16574 PMID: 34369076

26. Zhang X, Zhang P, An L, Sun N, Peng L, Tang W, Ma D, Chen J. Miltirone induces cell death in hepatocellular carcinoma cell through GSDME-dependent pyroptosis. Acta Pharm Sin B. 2020; 10:1397-413. https://doi.org/10.1016/i.apsb.2020.06.015 PMID:32963939

27. Zhang CC, Li CG, Wang YF, Xu LH, He XH, Zeng QZ, Zeng CY, Mai FY, Hu B, Ouyang DY. Chemotherapeutic paclitaxel and cisplatin differentially induce pyroptosis in A549 lung cancer cells via caspase3/GSDME activation. Apoptosis. 2019; 24:312-25. https://doi.org/10.1007/s10495-019-01515-1 PMID:

28. Tan G, Huang C, Chen J, Zhi F. HMGB1 released from GSDME-mediated pyroptotic epithelial cells participates in the tumorigenesis of colitis-associated colorectal cancer through the ERK1/2 pathway. J Hematol Oncol. 2020; 13:149. https://doi.org/10.1186/s13045-020-00985-0 PMID:33160389

29. Engl T, Rutz J, Maxeiner S, Juengel E, Roos F, Khoder W, Bechstein WO, Nelson K, Tsaur I, Haferkamp A, Blaheta RA. mTOR inhibition reduces growth and adhesion of hepatocellular carcinoma cells in vitro. Mol Med Rep. 2017; 16:7064-71.

https://doi.org/10.3892/mmr.2017.7401 PMID:28901501

30. Fu Q, Zhang Q, Lou Y, Yang J, Nie G, Chen Q, Chen Y, Zhang J, Wang J, Wei T, Qin H, Dang X, Bai X, Liang T. Primary tumor-derived exosomes facilitate metastasis by regulating adhesion of circulating tumor cells via SMAD3 in liver cancer. Oncogene. 2018; 37:6105-18. https://doi.org/10.1038/s41388-018-0391-0 PMID:29991801

31. Peng JM, Lin SH, Yu MC, Hsieh SY. CLIC1 recruits PIP5K1A/C to induce cell-matrix adhesions for tumor metastasis. J Clin Invest. 2021; 131:e133525.

https://doi.org/10.1172/JCl133525

PMID: 33079727

32. Zhao J, Sun Y, Lin H, Chou F, Xiao Y, Jin R, Cai X, Chang C. Olaparib and enzalutamide synergistically suppress HCC progression via the AR-mediated miR-146a5p/BRCA1 signaling. FASEB J. 2020; 34:5877-91. https://doi.org/10.1096/fj.201903045RR PMID: $\underline{32134529}$

33. Ouyang $X$, Feng L, Liu G, Yao L, Wang Z, Liu S, Xiao Y, Zhang $G$. Androgen receptor (AR) decreases HCC cells migration and invasion via miR-325/ACP5 signaling. J Cancer. 2021; 12:1915-25.

https://doi.org/10.7150/jca.49200

PMID: $\underline{3753989}$

34. Li B, Severson E, Pignon JC, Zhao H, Li T, Novak J, Jiang P, Shen H, Aster JC, Rodig S, Signoretti S, Liu JS, Liu XS. Comprehensive analyses of tumor immunity: implications for cancer immunotherapy. Genome Biol. 2016; 17:174.

https://doi.org/10.1186/s13059-016-1028-7 PMID:27549193

35. Ye L, Zhang T, Kang Z, Guo G, Sun Y, Lin K, Huang Q, Shi X, Ni Z, Ding N, Zhao KN, Chang W, Wang J, et al. Tumor-Infiltrating Immune Cells Act as a Marker for Prognosis in Colorectal Cancer. Front Immunol. 2019; 10:2368.

https://doi.org/10.3389/fimmu.2019.02368 PMID: $\underline{31681276}$

36. Hu C, Liu $X$, Zeng $Y$, Liu J, Wu F. DNA methyltransferase inhibitors combination therapy for the treatment of solid tumor: mechanism and clinical application. Clin Epigenetics. 2021; 13:166.

https://doi.org/10.1186/s13148-021-01154-x PMID:34452630

37. Simpson DJ, Chandra T. Epigenetic age prediction. Aging Cell. 2021; 20:e13452.

https://doi.org/10.1111/acel.13452 PMID: 34415665

38. Chandrashekar DS, Bashel B, Balasubramanya SAH, Creighton CJ, Ponce-Rodriguez I, Chakravarthi BVS, Varambally S. UALCAN: A Portal for Facilitating Tumor Subgroup Gene Expression and Survival Analyses. Neoplasia. 2017; 19:649-58.

https://doi.org/10.1016/j.neo.2017.05.002 PMID:28732212

39. Asplund A, Edqvist PH, Schwenk JM, Pontén F. Antibodies for profiling the human proteome-The 
Human Protein Atlas as a resource for cancer research. Proteomics. 2012; 12:2067-77.

https://doi.org/10.1002/pmic.201100504

PMID:22623277

40. Li J, Hu K, He D, Zhou L, Wang Z, Tao Y. Prognostic Value of PLXND1 and TGF- $\beta 1$ Coexpression and Its Correlation with Immune Infiltrates in Hepatocellular Carcinoma. Front Oncol. 2021; 10:604131. https://doi.org/10.3389/fonc.2020.604131 PMID:33489909

41. Deng JL, Xu YH, Wang G. Identification of Potential Crucial Genes and Key Pathways in Breast Cancer Using Bioinformatic Analysis. Front Genet. 2019; 10:695.

https://doi.org/10.3389/fgene.2019.00695 PMID:31428132

42. Gyorffy B, Lánczky A, Szállási Z. Implementing an online tool for genome-wide validation of survivalassociated biomarkers in ovarian-cancer using microarray data from 1287 patients. Endocr Relat Cancer. 2012; 19:197-208. https://doi.org/10.1530/ERC-11-0329 PMID:22277193

43. Gao J, Aksoy BA, Dogrusoz U, Dresdner G, Gross B, Sumer SO, Sun $Y$, Jacobsen A, Sinha R, Larsson E, Cerami E, Sander C, Schultz N. Integrative analysis of complex cancer genomics and clinical profiles using the cBioPortal. Sci Signal. 2013; 6:pl1. https://doi.org/10.1126/scisignal.2004088 PMID:23550210

44. Li J, Hu K, Zhou L, Huang J, Zeng S, Xu Z, Yan Y. Spectrum of Mesenchymal-Epithelial Transition Aberrations and Potential Clinical Implications: Insights From Integrative Pancancer Analysis. Front Oncol. 2020; 10:560615. https://doi.org/10.3389/fonc.2020.560615 PMID:33178590
45. Doncheva NT, Morris JH, Gorodkin J, Jensen LJ. Cytoscape StringApp: Network Analysis and Visualization of Proteomics Data. J Proteome Res. 2019; 18:623-32.

https://doi.org/10.1021/acs.jproteome.8b00702

PMID:30450911

46. Liao Y, Wang J, Jaehnig EJ, Shi Z, Zhang B. WebGestalt 2019: gene set analysis toolkit with revamped UIs and APIs. Nucleic Acids Res. 2019; 47:W199-205. https://doi.org/10.1093/nar/gkz401 PMID:31114916

47. Li T, Fu J, Zeng Z, Cohen D, Li J, Chen Q, Li B, Liu XS. TIMER2.0 for analysis of tumor-infiltrating immune cells. Nucleic Acids Res. 2020; 48:W509-14.

https://doi.org/10.1093/nar/gkaa407 PMID:32442275

48. Xiong Y, Wei Y, Gu Y, Zhang S, Lyu J, Zhang B, Chen C, Zhu J, Wang $\mathrm{Y}$, Liu $\mathrm{H}$, Zhang $\mathrm{Y}$. DiseaseMeth version 2.0: a major expansion and update of the human disease methylation database. Nucleic Acids Res. 2017; 45:D888-95. https://doi.org/10.1093/nar/gkw1123 PMID:27899673

49. Lv J, Liu H, Su J, Wu X, Liu H, Li B, Xiao X, Wang F, Wu $Q$, Zhang $Y$. DiseaseMeth: a human disease methylation database. Nucleic Acids Res. 2012; 40:D1030-35. https://doi.org/10.1093/nar/gkr1169 PMID:22135302 


\section{SUPPLEMENTARY MATERIALS}

\section{Supplementary Figures}

\section{A}

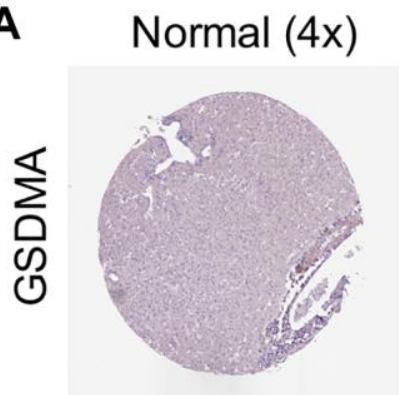

Staining: Not detected Antibody:

C

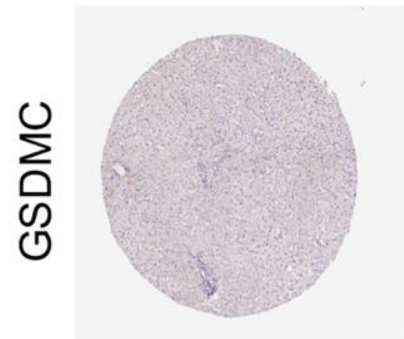

Staining: Not detected Antibody: HPA026317

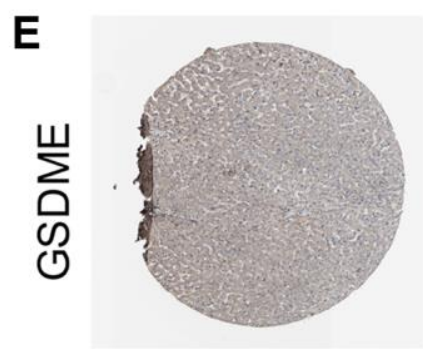

Staining: Low Antibody: HPA011326
B
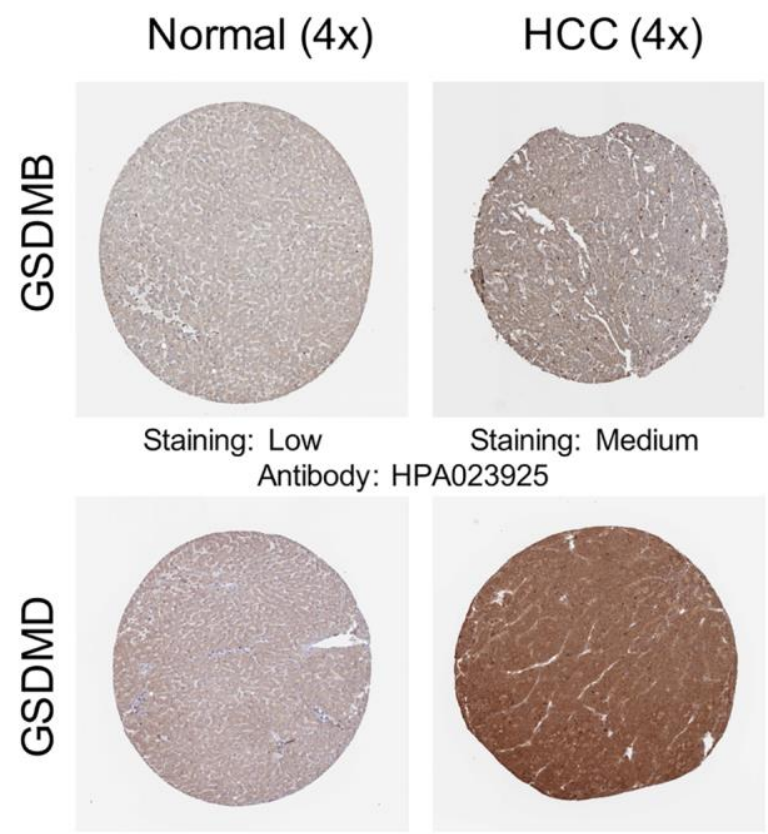

Staining: Medium Antibody: HPA044487

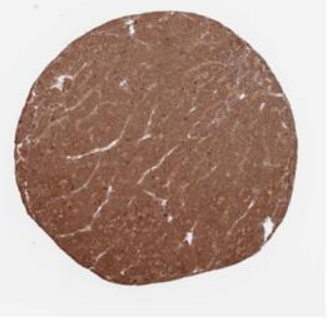

Staining: High

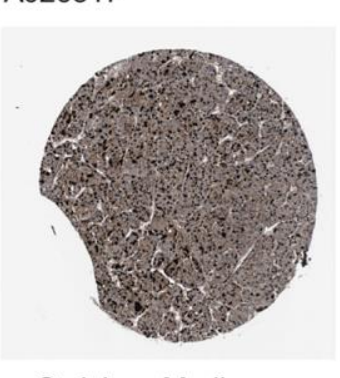

Staining: Medium

Supplementary Figure 1. Representative immunohistochemistry images of different GSDM family members between HCC tissues and normal liver tissues. (A-E) GSDMs protein expression data were retrieved from the THPA database (the Human Protein Atlas). 
A

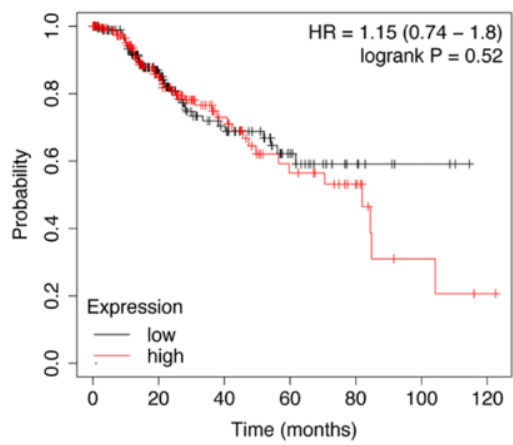

D

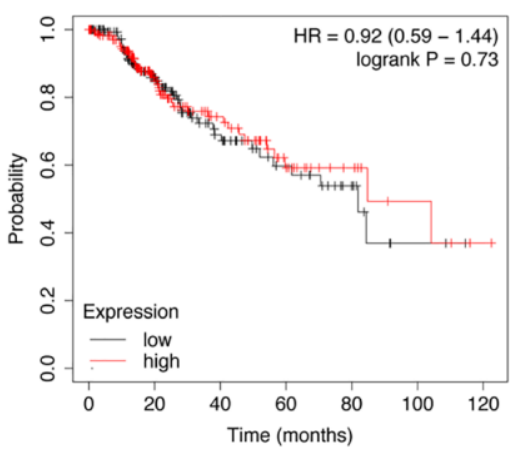

B

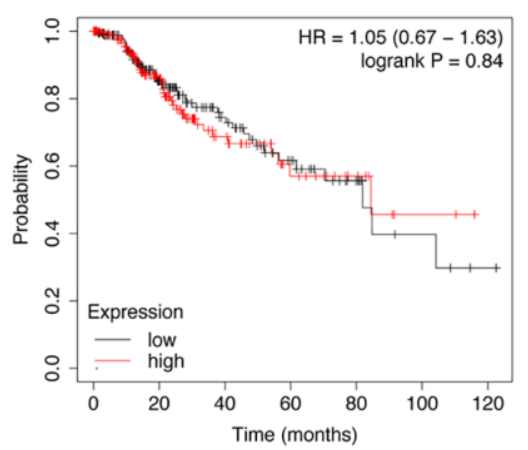

E

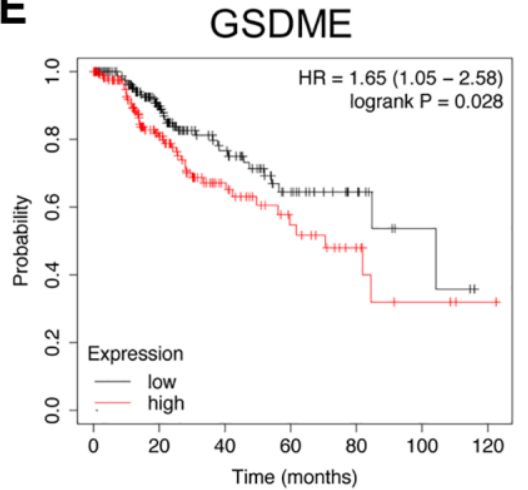

C

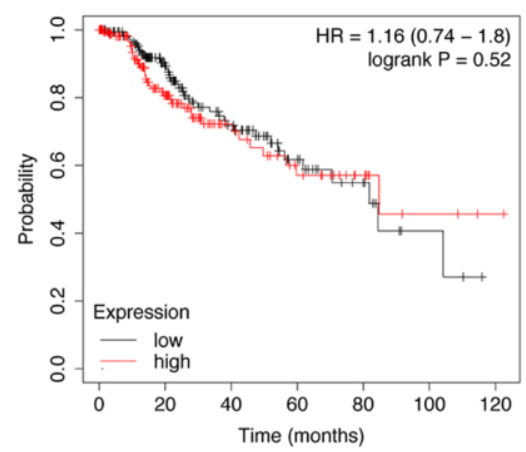

$\mathbf{F}$
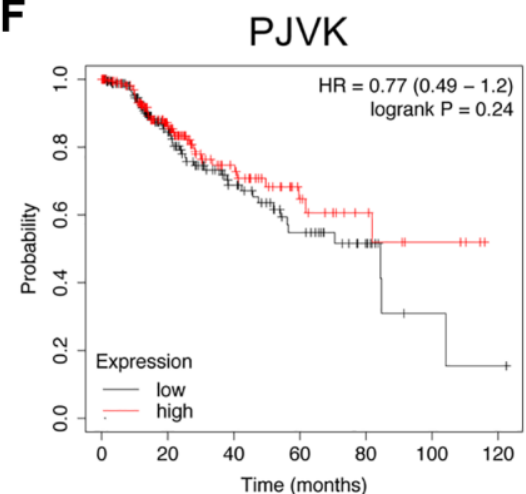

Supplementary Figure 2. Relationships between GSDMs mRNA expression levels and disease specific survival (DSS) of HCC patients (Kaplan-Meier plotter). (A-F) The disease specific survival (DSS) curve of six GSDM family members in patients with HCC. $P<$ 0.05 was considered as the cutoff with statistical significance. 

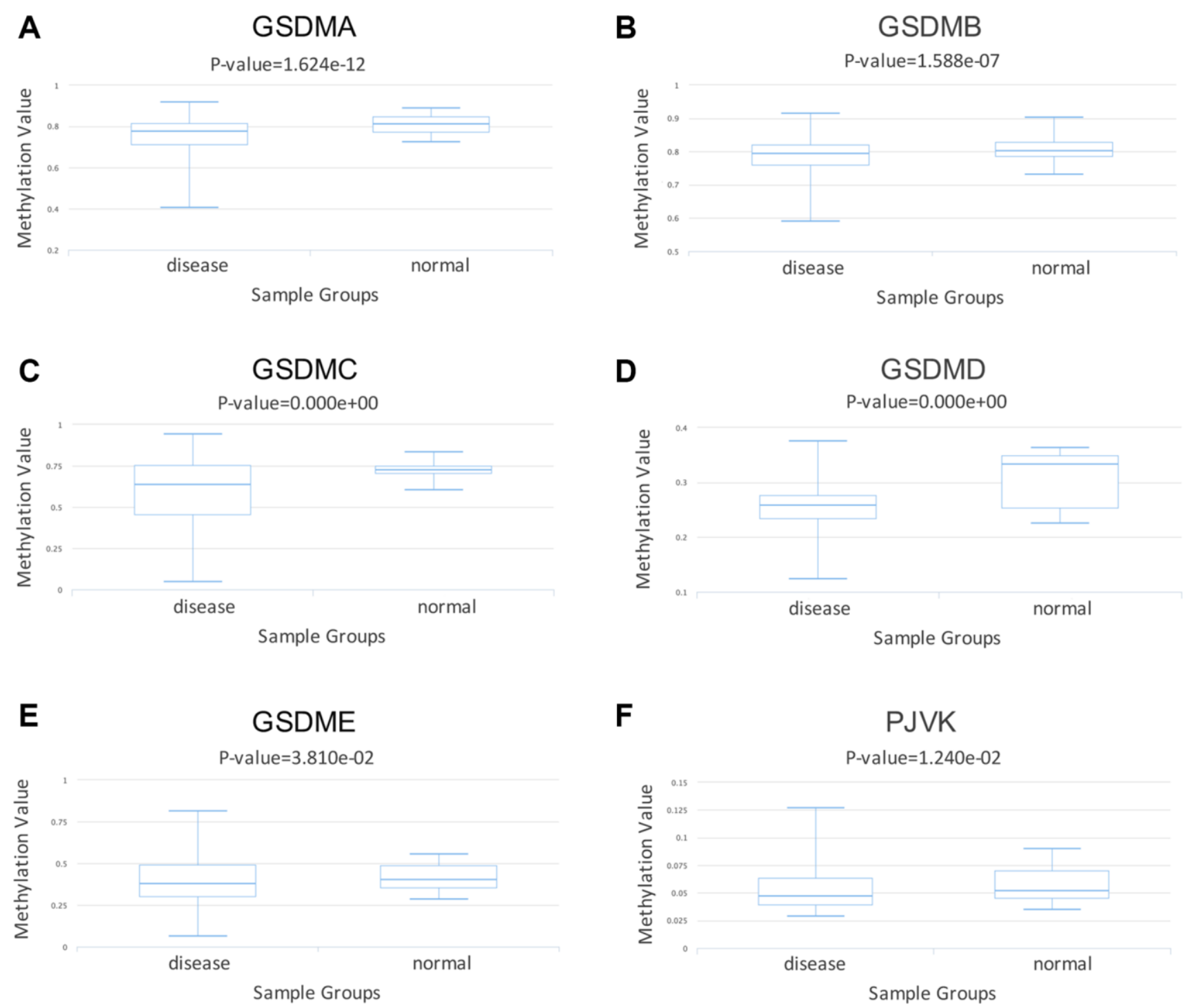

Supplementary Figure 3. DNA methylation levels of six GSDM family members in HCC. (A-F) The DNA methylation values of each GSDM family member between HCC tissues and normal liver tissues were evaluated by using DiseaseMeth. $P<0.05$ was considered as the cutoff with statistical significance. 


\section{Supplementary Tables}

Supplementary Table 1. Summary of bioinformatics database for analyzing the role of the GSDM family in HCC in this study.

\begin{tabular}{llll}
\hline Databases & Authors & Samples & Homepage links \\
\hline UALCAN & Chandrashekar DS & Tissues & $\underline{\text { http://ualcan.path.uab.edu/index.html }}$ \\
GEPIA2 & Tang Z, et al. & Tissues & $\underline{\text { http://gepia.cancer-pku.cn }}$ \\
The Human Protein Atlas & Anna Asplund, et al. & Tissues & $\underline{\mathrm{https} / / / \text { www.proteinatlas.org }}$ \\
Kaplan-Meier plotter & Gyorffy B, et al. & Tissues & $\underline{\mathrm{http}: / / \mathrm{kmplot} . \text { com/analysis }}$ \\
cBioPortal & Cerami E, et al. & Tissues & $\underline{\mathrm{http}: / / \text { www.cbioportal.org }}$ \\
WebGestalt & Liao Y, et al. & - & $\underline{\mathrm{http}: / / \text { webgestalt.org }}$ \\
Cytoscape & Doncheva NT, et al. & - & - \\
TIMER2.0 & Li T, et al. & Tissues & $\underline{\mathrm{https} / / / \text { cistrome.shinyapps.io/timer }}$ \\
DiseaseMeth 2.0 & Xiong Y, et al. & Tissues & $\underline{\mathrm{http}: / / \text { bio-bigdata.hrbmu.edu.cn/diseasemeth }}$ \\
\hline
\end{tabular}

Supplementary Table 2. The GSDM-associated co-expressed molecules in HCC.

\begin{tabular}{|c|c|c|c|}
\hline Gene & Log Ratio & $p$-Value & expression \\
\hline RECQL4 & 1.13 & $1.83 \mathrm{E}-15$ & Altered group \\
\hline ZNF281 & -1.24 & $1.94 \mathrm{E}-14$ & Unaltered group \\
\hline PPTC7 & -1.38 & $7.95 \mathrm{E}-14$ & Unaltered group \\
\hline ERN1 & -1.26 & $1.21 \mathrm{E}-13$ & Unaltered group \\
\hline ZNF366 & -1.21 & $4.04 \mathrm{E}-13$ & Unaltered group \\
\hline NFIC & -1.1 & $5.82 \mathrm{E}-13$ & Unaltered group \\
\hline CCNT1 & -1.32 & $1.72 \mathrm{E}-12$ & Unaltered group \\
\hline SPATA13 & -1.32 & $3.08 \mathrm{E}-12$ & Unaltered group \\
\hline ROBO3 & 1.07 & $4.49 \mathrm{E}-12$ & Altered group \\
\hline PROX1 & -1.32 & $6.01 \mathrm{E}-12$ & Unaltered group \\
\hline UHMK1 & -1.33 & $7.34 \mathrm{E}-12$ & Unaltered group \\
\hline RAPGEF6 & -1.17 & $1.57 \mathrm{E}-11$ & Unaltered group \\
\hline GDF7 & -1.22 & $1.66 \mathrm{E}-11$ & Unaltered group \\
\hline SHPRH & -1.03 & $2.11 \mathrm{E}-11$ & Unaltered group \\
\hline IL6ST & -1.6 & $2.24 \mathrm{E}-11$ & Unaltered group \\
\hline GTF2A1 & -1.15 & $2.27 \mathrm{E}-11$ & Unaltered group \\
\hline HIPK3 & -1.36 & $2.31 \mathrm{E}-11$ & Unaltered group \\
\hline RALGAPA2 & -1.19 & $2.41 \mathrm{E}-11$ & Unaltered group \\
\hline HACD2 & -1.39 & $2.97 \mathrm{E}-11$ & Unaltered group \\
\hline PCDHGB7 & -1.29 & $6.17 \mathrm{E}-11$ & Unaltered group \\
\hline USP12 & -1.13 & $6.50 \mathrm{E}-11$ & Unaltered group \\
\hline ZKSCAN8 & -1.34 & $8.05 \mathrm{E}-11$ & Unaltered group \\
\hline HS3ST3B1 & -1.28 & $9.82 \mathrm{E}-11$ & Unaltered group \\
\hline DDI2 & -1.41 & $1.19 \mathrm{E}-10$ & Unaltered group \\
\hline PVT1 & 1.14 & $1.20 \mathrm{E}-10$ & Altered group \\
\hline NBPF10 & -1.31 & $1.55 \mathrm{E}-10$ & Unaltered group \\
\hline PRR34-AS1 & 1.02 & $1.76 \mathrm{E}-10$ & Altered group \\
\hline ANKRD36BP1 & -1.23 & $1.93 \mathrm{E}-10$ & Unaltered group \\
\hline KIAA0754 & -1.22 & $2.02 \mathrm{E}-10$ & Unaltered group \\
\hline SYNC & 1.86 & $2.05 \mathrm{E}-10$ & Altered group \\
\hline SERINC5 & -1.11 & $2.12 \mathrm{E}-10$ & Unaltered group \\
\hline REST & -1.19 & $2.28 \mathrm{E}-10$ & Unaltered group \\
\hline ETV3 & -1.08 & $2.41 \mathrm{E}-10$ & Unaltered group \\
\hline ONECUT1 & -1.16 & $2.46 \mathrm{E}-10$ & Unaltered group \\
\hline FNIP2 & -1.2 & $2.52 \mathrm{E}-10$ & Unaltered group \\
\hline GPR75 & -1.09 & $4.29 \mathrm{E}-10$ & Unaltered group \\
\hline PCDHGA6 & -1.05 & $4.76 \mathrm{E}-10$ & Unaltered group \\
\hline GPR17 & -1.05 & $5.62 \mathrm{E}-10$ & Unaltered group \\
\hline ZDHHC20 & -1.2 & $7.82 \mathrm{E}-10$ & Unaltered group \\
\hline TNFRSF18 & 1.1 & $9.24 \mathrm{E}-10$ & Altered group \\
\hline PCDHGA12 & -1.27 & $1.26 \mathrm{E}-09$ & Unaltered group \\
\hline CDKL5 & -1.09 & $1.40 \mathrm{E}-09$ & Unaltered group \\
\hline $\mathrm{DBH}$ & -1.2 & $1.61 \mathrm{E}-09$ & Unaltered group \\
\hline NBPF9 & -1.16 & $1.82 \mathrm{E}-09$ & Unaltered group \\
\hline
\end{tabular}




\begin{tabular}{|c|c|c|c|}
\hline GHR & -1.11 & $1.96 \mathrm{E}-09$ & Unaltered group \\
\hline TNFSF12-TNFSF13 & 1.36 & 2.19E-09 & Altered group \\
\hline SBNO1 & -1.15 & $2.20 \mathrm{E}-09$ & Unaltered group \\
\hline TGFBRAP1 & -1.08 & $2.28 \mathrm{E}-09$ & Unaltered group \\
\hline PCDHGA2 & -1.48 & 2.30E-09 & Unaltered group \\
\hline PCDHGB6 & -1.17 & $2.57 \mathrm{E}-09$ & Unaltered group \\
\hline N4BP2 & -1.11 & $2.97 \mathrm{E}-09$ & Unaltered group \\
\hline SLC30A4 & -1.06 & $4.50 \mathrm{E}-09$ & Unaltered group \\
\hline ADAMTSL3 & -1.23 & 4.54E-09 & Unaltered group \\
\hline ITGB3 & -1.1 & $6.08 \mathrm{E}-09$ & Unaltered group \\
\hline NIPAL1 & -1.24 & $6.81 \mathrm{E}-09$ & Unaltered group \\
\hline CLVS1 & 1.44 & $8.04 \mathrm{E}-09$ & Altered group \\
\hline FAT4 & -1.07 & 8.57E-09 & Unaltered group \\
\hline AOC4P & -1.19 & $1.13 \mathrm{E}-08$ & Unaltered group \\
\hline LY6E & 1.24 & $1.59 \mathrm{E}-08$ & Altered group \\
\hline SELENOM & 1.11 & $1.63 \mathrm{E}-08$ & Altered group \\
\hline SUCNR1 & -1.08 & $1.82 \mathrm{E}-08$ & Unaltered group \\
\hline GOLIM4 & -1.03 & $2.66 \mathrm{E}-08$ & Unaltered group \\
\hline NFATC2 & -1.25 & $3.98 \mathrm{E}-08$ & Unaltered group \\
\hline S100A9 & 1.17 & $5.70 \mathrm{E}-08$ & Altered group \\
\hline TNNT1 & 1.41 & $6.92 \mathrm{E}-08$ & Altered group \\
\hline PARD3B & -1.02 & $7.46 \mathrm{E}-08$ & Unaltered group \\
\hline LY96 & 1.01 & $1.37 \mathrm{E}-07$ & Altered group \\
\hline DAB 1 & -1.12 & $1.51 \mathrm{E}-07$ & Unaltered group \\
\hline PKIB & 1.24 & $1.77 \mathrm{E}-07$ & Altered group \\
\hline S100A2 & 1.04 & $1.96 \mathrm{E}-07$ & Altered group \\
\hline AQP7P3 & 1.1 & $2.35 \mathrm{E}-07$ & Altered group \\
\hline GOLGA6B & -1.24 & 2.69E-07 & Unaltered group \\
\hline SFN & 1.55 & $2.70 \mathrm{E}-07$ & Altered group \\
\hline MMP9 & 1.29 & $3.88 \mathrm{E}-07$ & Altered group \\
\hline ADRA1A & -1.34 & 3.89E-07 & Unaltered group \\
\hline SYNE4 & 1.03 & $4.48 \mathrm{E}-07$ & Altered group \\
\hline PPARGC1A & -1.17 & $4.61 \mathrm{E}-07$ & Unaltered group \\
\hline UBD & 1.1 & 5.23E-07 & Altered group \\
\hline GPX2 & 1.46 & $5.42 \mathrm{E}-07$ & Altered group \\
\hline INS-IGF2 & -1.84 & 7.91E-07 & Unaltered group \\
\hline PCDHGA3 & -1.1 & $8.65 \mathrm{E}-07$ & Unaltered group \\
\hline PCDHB8 & -1.06 & $8.81 \mathrm{E}-07$ & Unaltered group \\
\hline NCOA2 & -1.05 & $9.29 \mathrm{E}-07$ & Unaltered group \\
\hline PDE3A & -1.06 & $1.01 \mathrm{E}-06$ & Unaltered group \\
\hline FBXW10 & 1.3 & $1.01 \mathrm{E}-06$ & Altered group \\
\hline KIRREL1 & -1.15 & $1.12 \mathrm{E}-06$ & Unaltered group \\
\hline TNNI3 & 1.01 & $1.21 \mathrm{E}-06$ & Altered group \\
\hline FAM66D & 1.04 & $1.22 \mathrm{E}-06$ & Altered group \\
\hline IGFALS & -1.4 & $1.41 \mathrm{E}-06$ & Unaltered group \\
\hline SLC5A11 & 1.32 & $1.57 \mathrm{E}-06$ & Altered group \\
\hline AP1M2 & 1.92 & $1.71 \mathrm{E}-06$ & Altered group \\
\hline CRYAB & 1.05 & $1.83 \mathrm{E}-06$ & Altered group \\
\hline SLC6A1 & -1.01 & $2.05 \mathrm{E}-06$ & Unaltered group \\
\hline PCDHGB5 & -1.15 & $2.16 \mathrm{E}-06$ & Unaltered group \\
\hline TRIM16L & 1.01 & $2.32 \mathrm{E}-06$ & Altered group \\
\hline PCDHGB2 & -1.06 & $3.82 \mathrm{E}-06$ & Unaltered group \\
\hline WASHC $2 \mathrm{~A}$ & -1.13 & 4.44E-06 & Unaltered group \\
\hline NQO1 & 1.54 & 4.57E-06 & Altered group \\
\hline PPP1R14D & 1.07 & 4.77E-06 & Altered group \\
\hline GGTLC2 & 1.07 & $5.89 \mathrm{E}-06$ & Altered group \\
\hline PCDHGA4 & -1.02 & $6.60 \mathrm{E}-06$ & Unaltered group \\
\hline INHBC & -1.01 & 7.35E-06 & Unaltered group \\
\hline TRIM54 & 1.17 & 7.70E-06 & Altered group \\
\hline AKR1B10 & 1.93 & $8.43 \mathrm{E}-06$ & Altered group \\
\hline AR & -1.19 & $9.37 \mathrm{E}-06$ & Unaltered group \\
\hline SNORD116-4 & -1.04 & $2.07 \mathrm{E}-05$ & Unaltered group \\
\hline FNDC5 & -1.37 & $2.12 \mathrm{E}-05$ & Unaltered group \\
\hline SPP1 & 1.59 & $2.73 \mathrm{E}-05$ & Altered group \\
\hline TINAG & 1.57 & $2.90 \mathrm{E}-05$ & Altered group \\
\hline GUCY2C & 1.38 & $3.83 \mathrm{E}-05$ & Altered group \\
\hline $\mathrm{ABCA} 8$ & -1.13 & $4.06 \mathrm{E}-05$ & Unaltered group \\
\hline AVPR1A & -1.26 & $4.39 \mathrm{E}-05$ & Unaltered group \\
\hline
\end{tabular}




\begin{tabular}{|c|c|c|c|}
\hline TRNP1 & 1.01 & $4.98 \mathrm{E}-05$ & Altered group \\
\hline FXYD3 & 1.32 & $5.65 \mathrm{E}-05$ & Altered group \\
\hline GPR37 & -1.07 & 5.79E-05 & Unaltered group \\
\hline GPLD1 & -1.1 & $6.01 \mathrm{E}-05$ & Unaltered group \\
\hline SPHK1 & 1.04 & $6.52 \mathrm{E}-05$ & Altered group \\
\hline GCNT3 & 1.14 & 7.47E-05 & Altered group \\
\hline MMP12 & 1.13 & 7.79E-05 & Altered group \\
\hline AKR1B15 & 1.33 & 8.03E-05 & Altered group \\
\hline LMTK3 & 1.06 & $8.07 \mathrm{E}-05$ & Altered group \\
\hline SLC39A4 & 1.06 & $8.38 \mathrm{E}-05$ & Altered group \\
\hline TAT & -1.37 & $1.18 \mathrm{E}-04$ & Unaltered group \\
\hline LCN2 & 1.4 & $1.23 \mathrm{E}-04$ & Altered group \\
\hline EPO & 1.19 & $1.27 \mathrm{E}-04$ & Altered group \\
\hline POPDC3 & 1.04 & $1.46 \mathrm{E}-04$ & Altered group \\
\hline GCGR & -1.49 & $1.65 \mathrm{E}-04$ & Unaltered group \\
\hline TMEM92 & 1.3 & $1.82 \mathrm{E}-04$ & Altered group \\
\hline PAPPA2 & -1.09 & $1.89 \mathrm{E}-04$ & Unaltered group \\
\hline PTGES & 1.09 & $2.20 \mathrm{E}-04$ & Altered group \\
\hline PNCK & 1.1 & 3.30E-04 & Altered group \\
\hline PITX1 & 1.21 & 4.42E-04 & Altered group \\
\hline CLDN4 & 1.2 & $4.70 \mathrm{E}-04$ & Altered group \\
\hline SAA1 & 1.39 & $5.80 \mathrm{E}-04$ & Altered group \\
\hline HHIPL2 & 1.05 & $5.88 \mathrm{E}-04$ & Altered group \\
\hline PAGE1 & 1.02 & $6.38 \mathrm{E}-04$ & Altered group \\
\hline CYP2A13 & -1.05 & $7.10 \mathrm{E}-04$ & Unaltered group \\
\hline SPINK1 & 1.57 & $7.36 \mathrm{E}-04$ & Altered group \\
\hline CNDP1 & -1.2 & $7.85 \mathrm{E}-04$ & Unaltered group \\
\hline CYP4A22 & -1.01 & $8.54 \mathrm{E}-04$ & Unaltered group \\
\hline AGR2 & 1.33 & $9.43 \mathrm{E}-04$ & Altered group \\
\hline AFP & 1.41 & $9.51 \mathrm{E}-04$ & Altered group \\
\hline ADAMTS16 & -1.02 & $1.03 \mathrm{E}-03$ & Unaltered group \\
\hline HSD17B13 & -1.4 & $1.06 \mathrm{E}-03$ & Unaltered group \\
\hline CYP3A4 & -1.54 & $1.07 \mathrm{E}-03$ & Unaltered group \\
\hline GAGE4 & 1.02 & $1.23 \mathrm{E}-03$ & Altered group \\
\hline UGT2A1 & 1.03 & $1.30 \mathrm{E}-03$ & Altered group \\
\hline UGT1A4 & -1.23 & $1.58 \mathrm{E}-03$ & Unaltered group \\
\hline ALDH3A1 & 1.43 & $1.60 \mathrm{E}-03$ & Altered group \\
\hline RPS4Y1 & 1.64 & $1.85 \mathrm{E}-03$ & Altered group \\
\hline S100P & 1.28 & $1.90 \mathrm{E}-03$ & Altered group \\
\hline PDZK1IP1 & 1.18 & $2.05 \mathrm{E}-03$ & Altered group \\
\hline C9 & 1.36 & $2.75 \mathrm{E}-03$ & Altered group \\
\hline SAA2 & 1.24 & $3.13 \mathrm{E}-03$ & Altered group \\
\hline XIST & -1.55 & $3.48 \mathrm{E}-03$ & Unaltered group \\
\hline FAM133A & 1.02 & 4.14E-03 & Altered group \\
\hline HSD11B1 & -1.01 & $4.61 \mathrm{E}-03$ & Unaltered group \\
\hline PRSS3 & 1.12 & $4.90 \mathrm{E}-03$ & Altered group \\
\hline CPLX2 & 1.34 & $5.46 \mathrm{E}-03$ & Altered group \\
\hline BPIFB2 & 1.03 & $9.51 \mathrm{E}-03$ & Altered group \\
\hline SLC22A12 & 1.02 & $9.70 \mathrm{E}-03$ & Altered group \\
\hline IGF2 & -1.11 & $9.83 \mathrm{E}-03$ & Unaltered group \\
\hline PGC & 1.19 & 0.0125 & Altered group \\
\hline REG1A & 1.14 & 0.0138 & Altered group \\
\hline APOA4 & 1.11 & 0.0169 & Altered group \\
\hline EIF1AY & 1.01 & 0.0191 & Altered group \\
\hline SLCO1B3 & -1.01 & 0.0228 & Unaltered group \\
\hline XAGE1B & 1.12 & 0.0315 & Altered group \\
\hline
\end{tabular}

